\title{
Application of seismogram synthesis to the study of earthquake source from strong motion records
}

\author{
Fabrice Cotton and Michel Campillo \\ Observatoire de Grenoble, Université Joseph Fourier, Grenoble, France
}

\begin{abstract}
We present the results of an analysis of the Michoacan and Landers earthquakes to constrain the kinematic description of the rupture process. The example of the Michoacan earthquake shows that a crack type model is better than a dislocation model to describe the displacement in the vicinity of the fault. We also show that this point is not in contradiction with the fact that the faulting appears to be a complex process. We attribute this complexity to instabilities in crack growth. The June 28 , Landers earthquake offers an exceptional opportunity to apply a new inversion technique to a major strike slip event. We model the rupture evolution including local differences in slip durations and variations in rupture velocity. The slip distribution shows that this event consists of a series of regions of high slip (sub-events) separated by regions of relative low slip. Our inversion favors the hypothesis that the duration of the slip at each point is of the order of the duration of the rupture of each sub-event and is consistent with a crack type process occurring during each sub-event. For such a large earthquake, the slip duration is however smaller than the total rupture duration.
\end{abstract}

Key words strong motion - earthquake source rise-time - inversion - Landers - Michoacan

\section{Introduction}

We compute synthetic seismograms to study the rupture process during large earthquakes. The uncertainties concerning the state of stress in the Earth and the friction on the faults are so important that we cannot use a universal source model that could be applied to particular cases. So, our purpose is modest and consists in testing the fundamental hypothesis on the rupture process. A key observation should be the time history of slip at a given point on the fault. In this respect, two scenarios are proposed:

- the dislocation type process in which the displacement on the fault is basically independent of the position and for which the duration of the slip at a point is small with respect to the total duration of the rupture process. Originally proposed for kinematic models (e.g. Aki, 1968), this type of process has recently been invoked to describe actual earthquakes. Brune (1970), Heaton (1990) and Brune et al. (1990) suggested physical explanations for such a behavior. For example, Brune's «normal motion hypothesis» should explain why there is no large scale interaction of the different parts of the fault during the dynamic process;

- the crack type process that corresponds basically to the development of an idealized crack in an elastic medium assuming Coulomb's friction law. In this case, the slip at each point depends on the slip on the entire fault and consequently the duration of the slip is of the order of the duration of the rupture process on the fault (Kostrov, 1964; Madariaga, 1976; Das and Aki, 1977). The end of the slip occurs at arrival at the point of the healing front that propagates from the periphery at the shear wave velocity. A refinement of 
this model consists in taking into account the heterogeneity of the properties of the fault (Das and Kostrov, 1988) and a friction law deduced from laboratory experiments in place of Coulomb's friction law (e.g. recently Madariaga and Cochard, 1992). We do not separate these two types of scenarios into kinematic or dynamic models since short rise time should be the consequence of a slip-rate dependent friction as suggested by Heaton (1990).

To find to which category the actual earthquake processes belong is important because it has implications on the determination of friction laws and on the origin of the complexity of the seismic signals.

We present two approaches to this problem using data from two large earthquakes: the 1985 Michoacan, Mexico earthquake $(M w=8.1)$ and the 1992 Landers, California earthquake $(M w=7.4)$. In both cases, we compare synthetic seismograms, computed in flat layered media for different rupture models, with observed ground motions. In a layered medium, Green's function may be computed very accurately. In the following, we use a discrete wave number representation (Bouchon, 1981) combined with the reflection-transmission matrix method (Kennett, 1983) to compute theoretical Green's functions. The extended sources are represented by arrays of point sources whose distance is less than one sixth of the smallest wavelength.

\section{The 1985 Michoacan earthquake}

On September 19, 1985, a large subduction earthquake occurred beneath the Mexican states of Michoacan and Guerrero. This earthquake produced huge damage in Mexico City, about $350 \mathrm{~km}$ away from the epicenter. This disaster was due to the large amplification of 2 to $4 \mathrm{~s}$ period waves by the sediments and the clay of the Mexico City Valley (e.g. SanchezSesma et al., 1988). Ripples with a period around $3 \mathrm{~s}$ superimposed on the long period source signals can be seen on local, regional and teleseismic records (Singh et al., 1990; Campillo et al., 1989). These ripples were emitted a few seconds after the start of the rupture. To identify the origin of these waves is a key problem for the assessment of seismic risk in Mexico City. At the same time we have here a clear example of rupture complexity during a large earthquake with a similar signature on different types of data.

We have an exceptional opportunity to study the slip history with the displacement records at the accelerometric station Caleta de Campos (Anderson et al., 1986). This station is close to the epicenter and shows the effect of the propagation of the rupture front beneath the station. As the subduction is gently dipping at an angle of about 15 degrees, the vertical component of displacement is close to corresponding directly to the transverse component with respect to the fault plane. As seen in fig. 1, the observed vertical displacement wave form is characterized by a smooth ramp reaching the static value. The wave form expected from a crack model and a dislocation model are different since the singularities of slip velocity at the rupture front are different for the two models (Aki and Richards, 1980). We used numerical modeling to test if a difference can be seen in the configuration corresponding to the record at Caleta de Campos. We built up a homogeneous dislocation model with a ramp function.

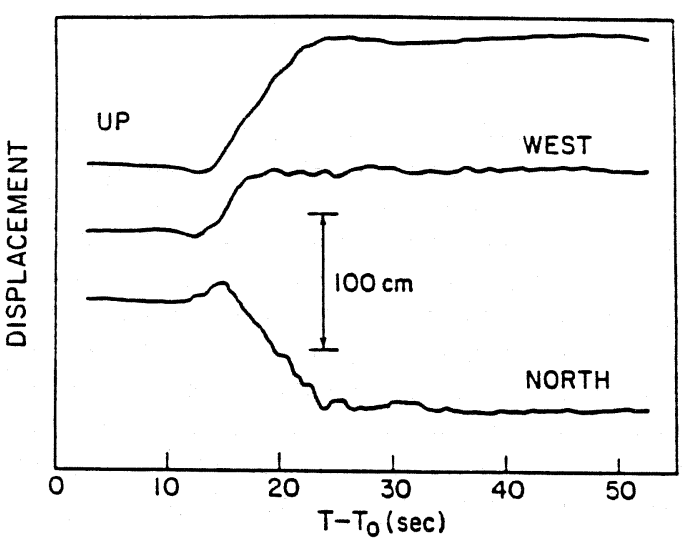

Fig. 1. Displacement records observed during the great Michoacan earthquake at the station Caleta de Campos located close to the epicenter and just above the fault zone (after Anderson et al., 1986). 
The rise time was chosen to be $4 \mathrm{~s}$. The self similar crack is a good approximation of a finite crack until the rupture stops, as shown by Madariaga (1976). To model the passing of the edge of the crack below the station, we set up a model depicted in fig. 2a, in which the slip distribution at each time is the one of a self similar circular crack. The center of the self similar crack is moving from the hypocenter to its final position when the crack stops. This model is useful only because the discontinuity of slip velocity at the tip is the one of a crack. Both models have a seismic moment equal to the one of the first subevent obtained from teleseismic records by Houston and Kanamori (1986). The source-receiver configurations are shown as surface view in fig. 2a together with the slip along the fault for the crack model. In the two models the rupture front propagates at a constant velocity equal to $75 \%$ of the shear wave velocity. Figure $2 \mathrm{~b}$ shows the synthetic displacements obtained for the two models at the locations indicated in fig. 2a. As suspected, the displacement produced by the dislocation model is very different from that of the crack model. The dislocation model implies an overshoot that is not present in the data. On the contrary, a model of crack growth shows the characteristics observed at Caleta de Campos. This means that at least the first part of the rupture process behaves as the growth of a large smooth crack. A similar conclusion was proposed by Yomogida (1988). This approach to analyze the slip function at the crack tip is limited to the cases where the integration of the accelerograms is sufficiently accurate to retrieve the static displacements and when the station is well located to record the passing of the rupture front.

Our conclusion that the first part of the rupture developed as a large crack may seem to contradict our previous statement that rupture complexity might have occurred to explain the existence of the 3 second period ripples. If the crack-like rupture required by the displacement records ruled out the hypothesis of a large heterogeneity of the slip on this part of the fault, it does not preclude a complexity of the history of the development of the crack. In order to check this hypothesis, we considered a self similar crack model whose rupture velocity changes. In this case the complexity of the ground motion is entirely due to the kinematics of the rupture front while the slip distribution is the same as for a constant velocity crack. In fig. 3, we present the synthetic velocities obtained for three different kinematics of the rupture front together with the observed vertical displacement at Caleta de Campos. The traces exhibit a complexity that is the image of the kinematics of the rupture front. In particular, the synthetics show the presence of ripples similar to the ones on the observed record. Therefore, changes in the rupture velocity of a large crack is a possible explanation for the complexity of the wave forms.

In conclusion, the displacement recorded at Caleta de Campos, i.e. just above the rupture, requires that the rupture developed as a large crack. This means, in terms of rupture physics, that the process involves interactions over a large area. The complexity of the observed seismograms at a shorter period is not in contradiction with this first conclusion since instabilities in the growth of a large crack, such as rupture velocity jumps, produce wave forms similar to the observed ones. The use of the shape of transverse displacement is restricted by the fact that the double integration of the accelerograms may not be as robust as the standard processing leading to band-passed velocities. Nevertheless, it provides a «direct» view of the phenomenon that cannot be achieved with inversion techniques that rely on remote records that are strongly affected by propagation. In the following, we shall present the use of an inversion technique to investigate the source process of a large earthquake.

\section{The 1992 Landers, California earthquake: a direct approach}

The Landers earthquake of June 28, 1992 produced large surface offsets in the Mojave Desert. These surface traces indicate at least two major directions of faulting (fig. 4). According to these observations we built up a preliminary rupture model (Campillo and Archuleta, 1993) that we constrained with the 


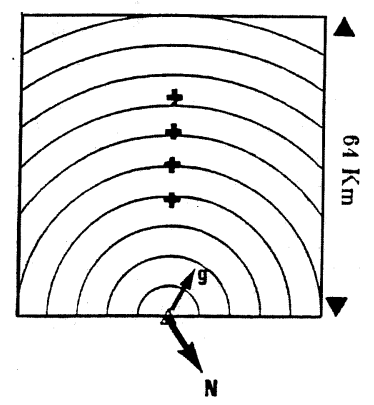

(a)
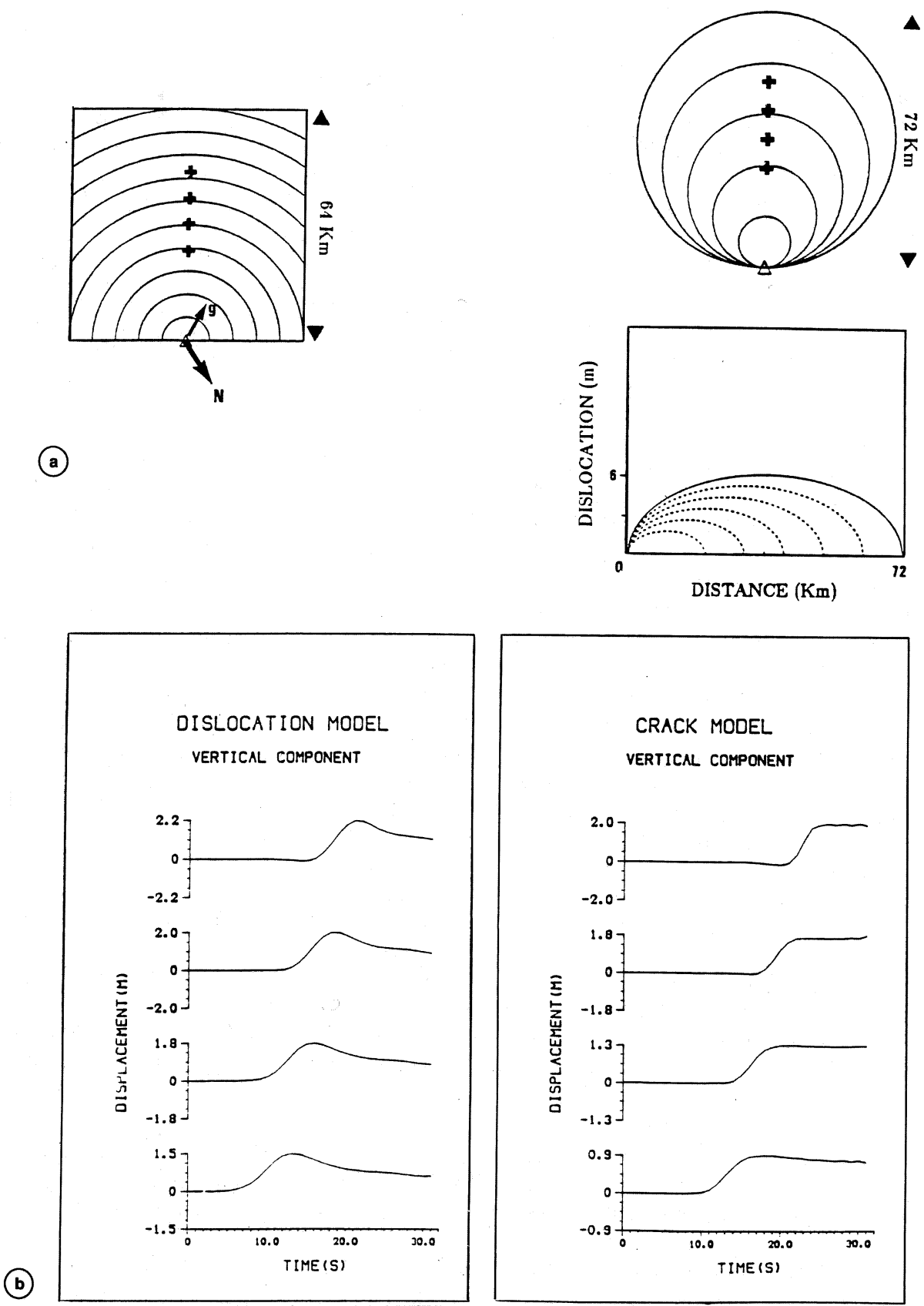

Fig. 2a,b. a) Source models used for computing synthetic seismograms: dislocation model (left) and crack model (right). The lines indicate the position of the rupture front at equal time intervals. The arrows $N$ and $g$ denote the direction of the north and of the slip. The crosses show the locations of the receivers at the earth surface. This figure shows the slip on the fault at equal time intervals for the crack model. b) Synthetic vertical displacements computed from these two models (adapted from Campillo et al., 1989). 


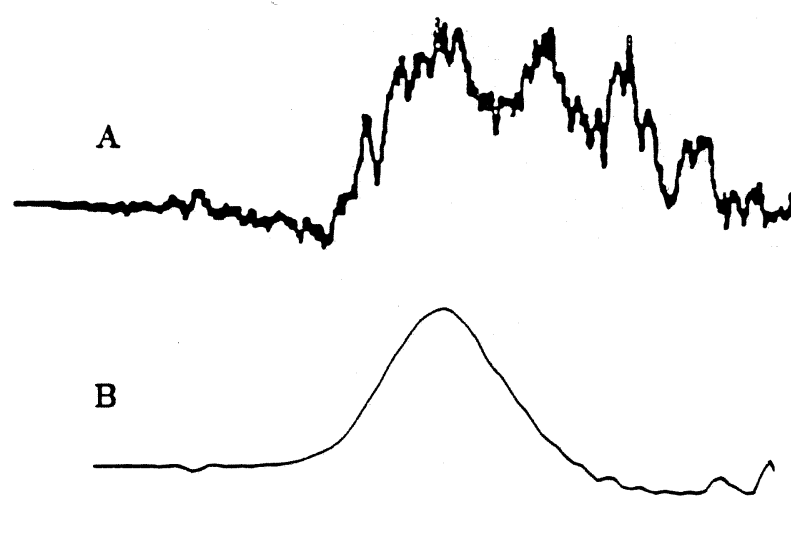

$V_{R}(\mathrm{~km} / \mathrm{sec})$

2.

1.
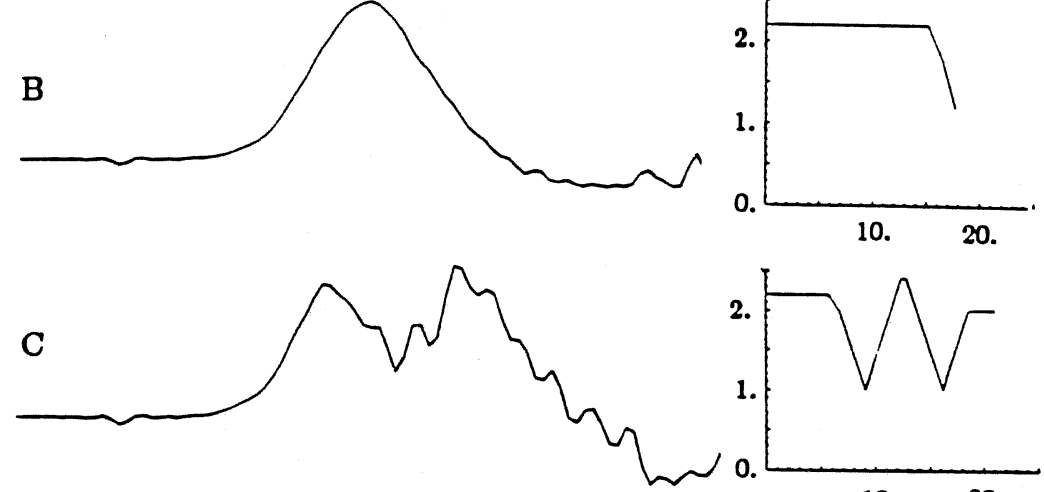

2.

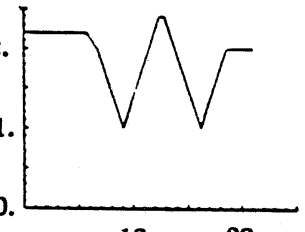

10.

20.

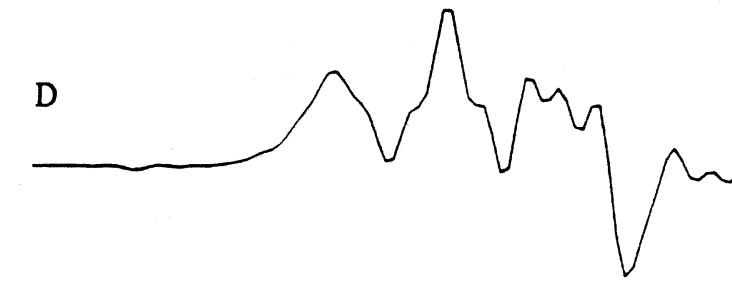

2.

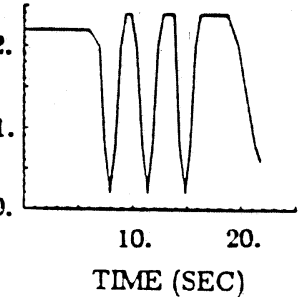

0 .

10.

TIME(SEC)

20.

30.

Fig. 3. (a) Vertical ground velocity recorded at Caleta de Campos, (b), (c) and (d) synthetic ground velocities computed for a crack model with variable rupture velocity. The time dependance is shown on the right side of each synthetic (after Campillo et al., 1989).

displacement records obtained at the TERRAscope stations PAS, SVD, PFO and GSC. We consider a fault model that consists of two segments. We assumed a uniform slip and a uniform rupture velocity (fig. 5) on each segment. The synthetics are computed in a crustal structure (table I) derived from the model proposed for Southern California by Kanamori and Hadley (1975). The presence of dispersed Love waves on certain records requires taking into account the superficial low velocity layer. Using a simple model characterized by a very small number of parameters we obtain a satisfactory agreement between the synthetics and the observations (fig. 6). In this case we assume a dislocation model, that is on each point of the fault segment the slip function is a ramp function with a constant final slip. The rise time and final slip are $4 \mathrm{~s}$ and $3.5 \mathrm{~m}$ for the first segment and $4 \mathrm{~s}$ and $5.2 \mathrm{~m}$ for the second segment. In this 
1992 Southern California Earthquake Sequences

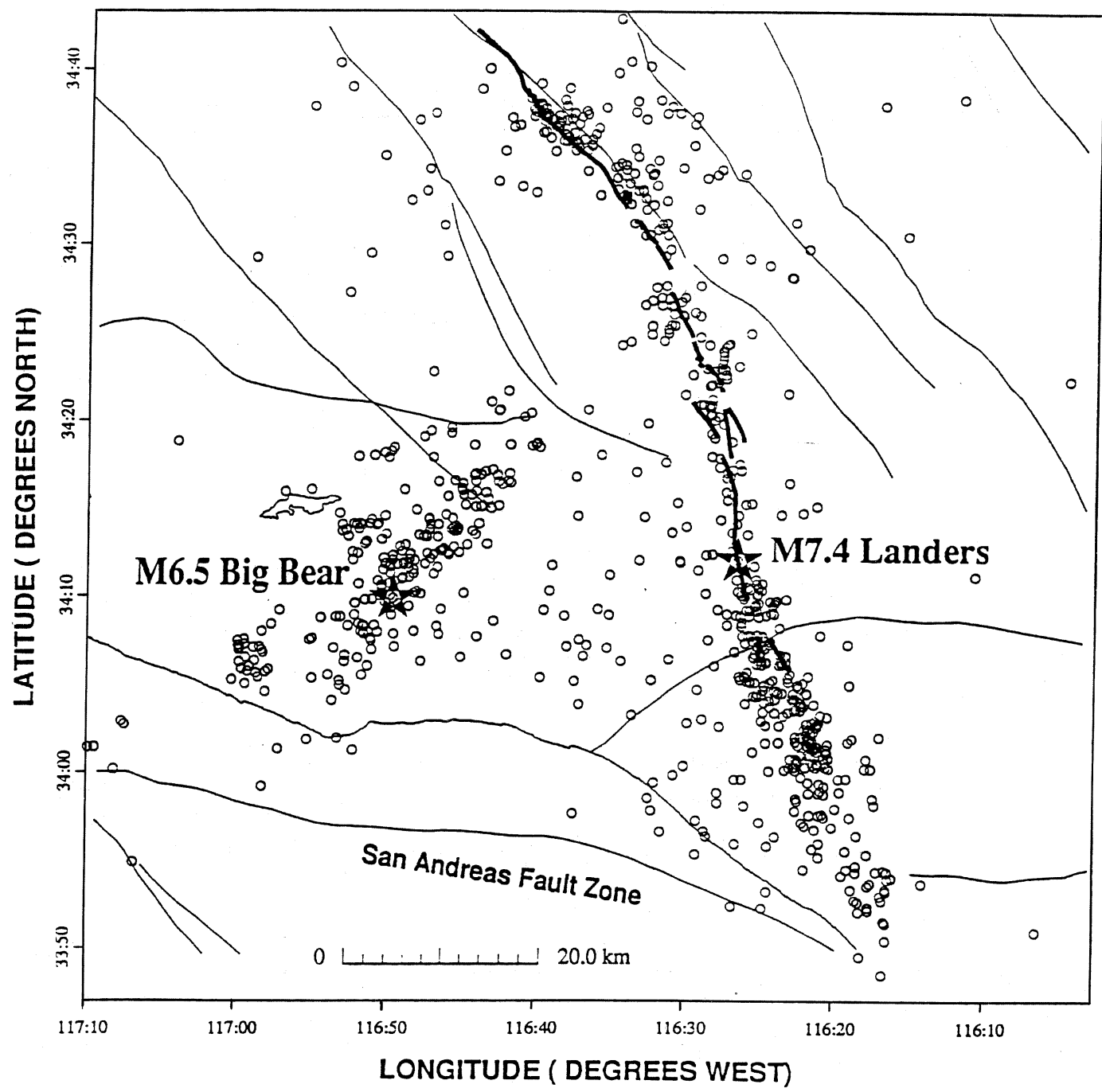

Fig. 4. Mapped surface ground rupture of the Landers earthquake (heavy lines). The stars indicate the epicenters of the Landers and Big Bear earthquakes while the circles represent the locations of the aftershocks.

model, there is a delay of $1 \mathrm{~s}$ between the end of the rupture on the first segment and the initiation of the rupture on the second one. This test indicates the accuracy of the numerical modeling. The misfit between simulation and observation obtained here with a small number of parameters is the upper bound of what can be expected from further more detailed studies. Large number of records were obtained in the epicentral region during the Landers earthquake which is probably the best case to achieve an inversion of the rupture process. 


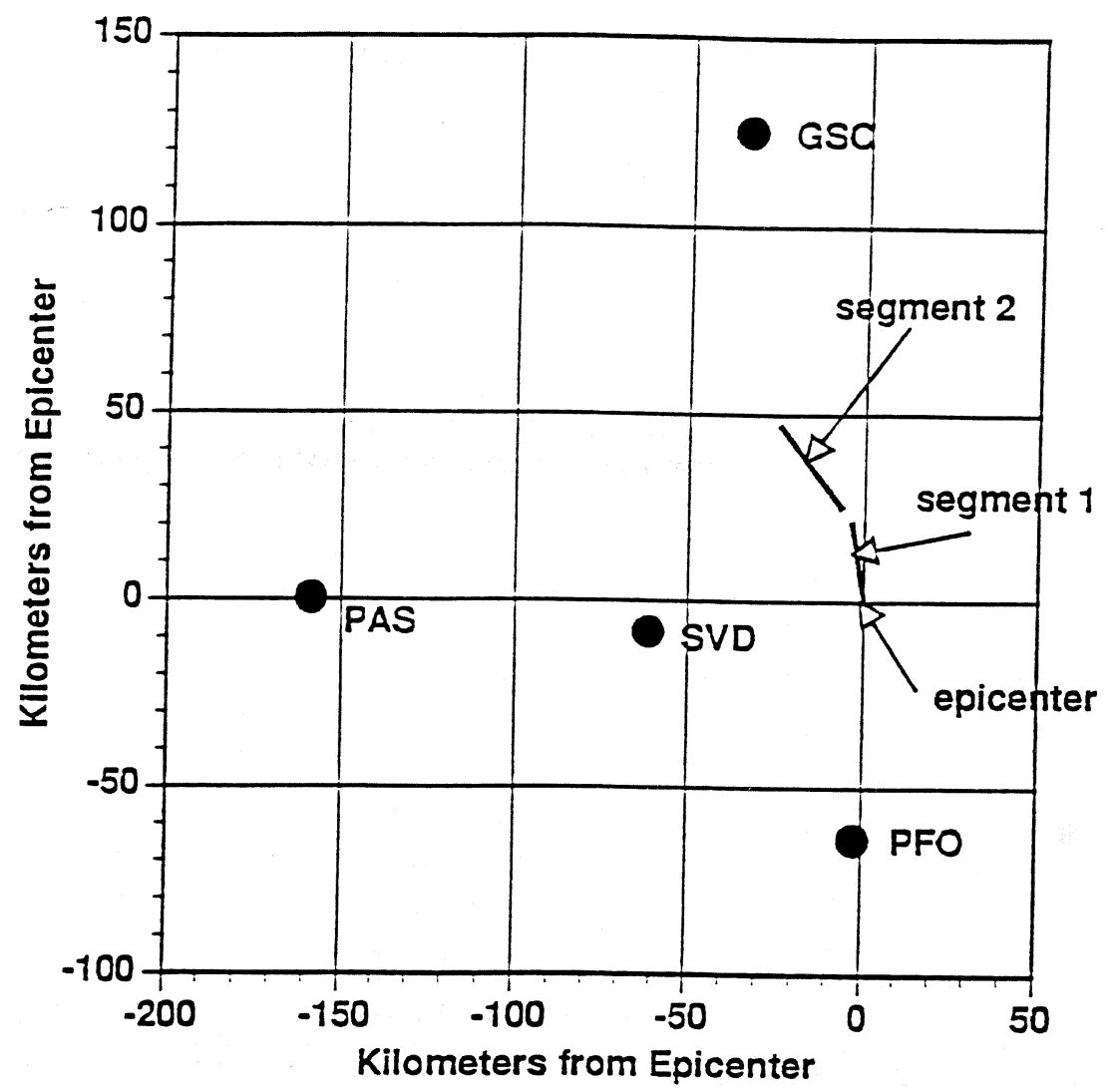

$\mathrm{S}$

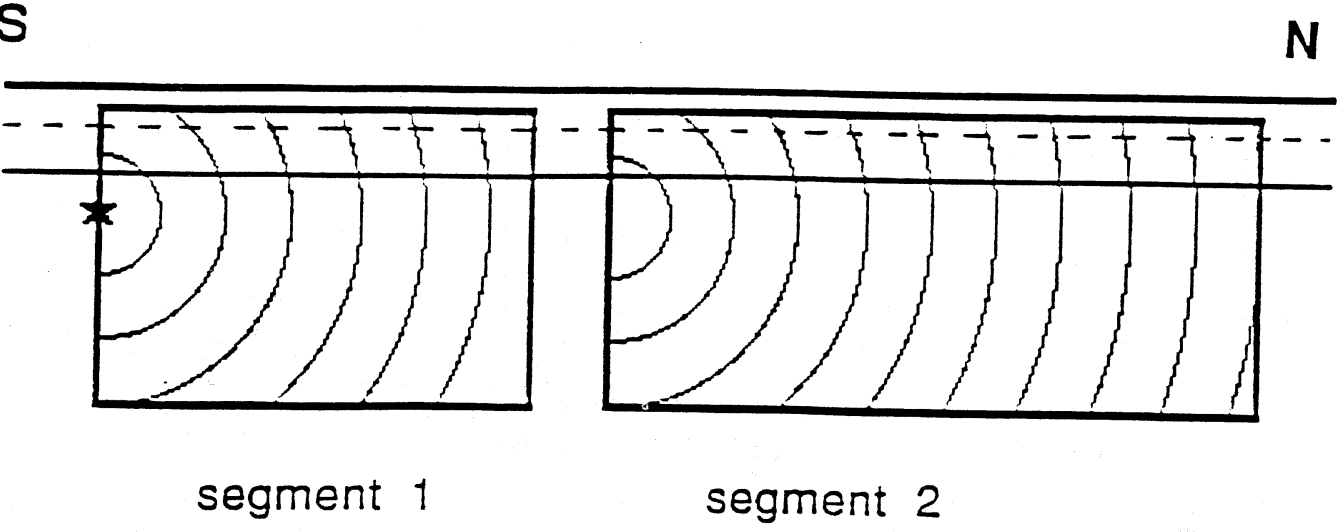

Fig. 5. Top: the two fault segments used to build a preliminary model and the location of the TERRAscope stations. Bottom: view of the fault segments indicating the propagation of the rupture front. The horizontal lines represent the interface in the flat layered crustal model used for the simulation (after Campillo and Archuleta, 1993). 
Table I. Crustal structure used in calculation of Green's function.

\begin{tabular}{cccccc}
\hline \hline Depth $(\mathrm{km})$ & $V p(\mathrm{~km} / \mathrm{s})$ & $V s(\mathrm{~km} / \mathrm{s})$ & Density $\left(\mathrm{g} / \mathrm{cm}^{3}\right)$ & $Q p$ & $Q s$ \\
\hline 0.0 & 4.1 & 2.3 & 2.5 & 300 & 300 \\
2.0 & 5.5 & 3.2 & 2.8 & 500 & 500 \\
4.0 & 6.3 & 3.65 & 2.9 & 500 & 500 \\
26.0 & 6.8 & 3.9 & 3.1 & 500 & 500 \\
32.0 & 8.2 & 4.7 & 3.2 & 500 & 500 \\
\hline
\end{tabular}
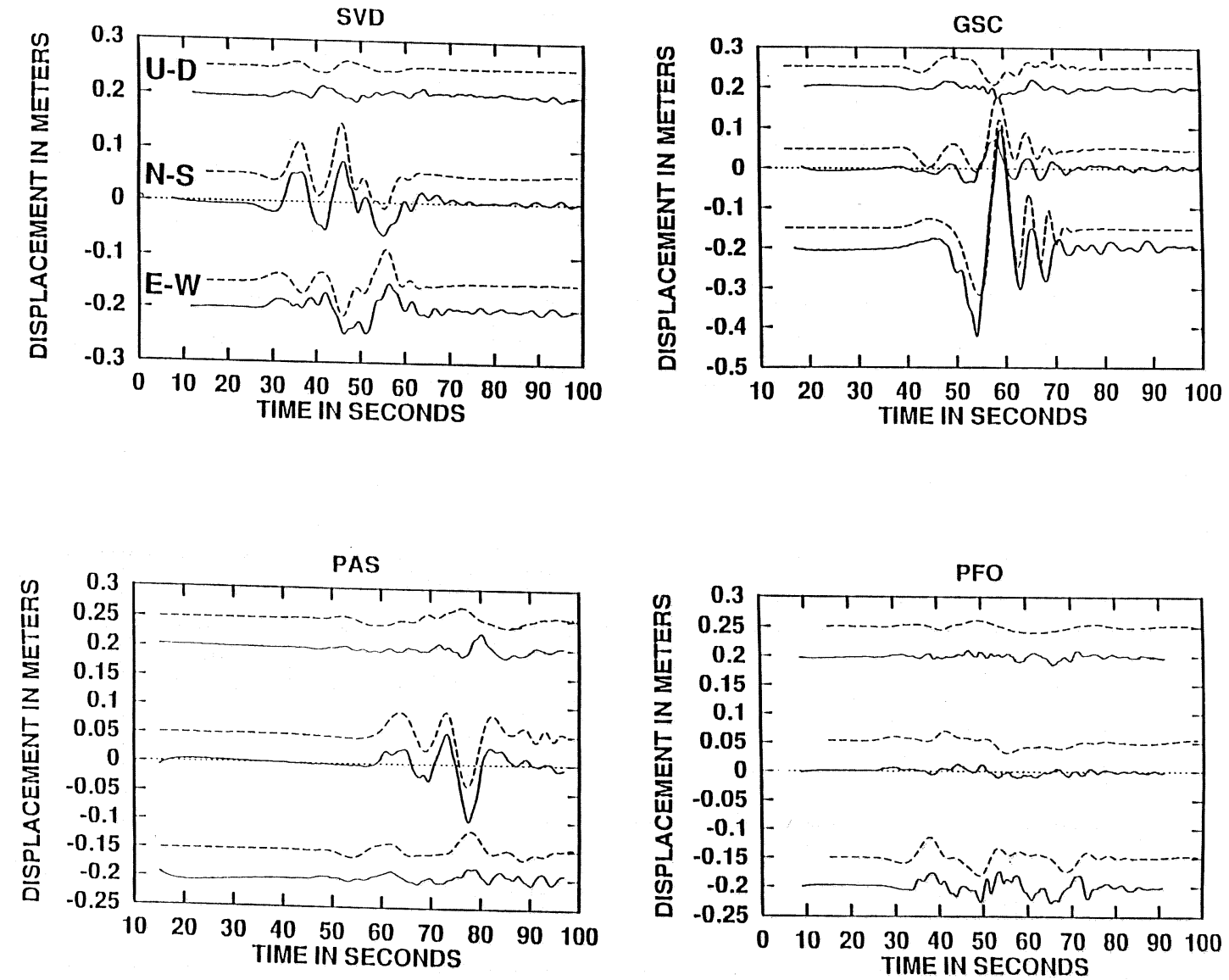

Fig. 6. Comparison between observed displacements (solid lines) and synthetics (dashed lines) (after Campillo and Archuleta, 1993). 


\section{The 1992 Landers, California earthquake: an inverse approach}

\subsection{Parameterization of a complex faulting model}

In order to obtain a more detailed model of the rupture process, we used a linearized inversion of the seismograms in the frequency domain (Cotton and Campillo, 1995). In this procedure we divide the fault plane into small rectangular regions of equal area called subfaults in the following. Each subfault is allowed to slip once. With this parameterization, the ground motion $(V)$ at a given station $i$ and a given frequency $\omega$ can be represented as a linear sum of $n$ subfault contributions, each appropriately delayed in time to account for front propagation.

$$
V_{i}(\omega)=\sum_{k=1}^{n} \operatorname{slip}(k) \exp ^{-i \omega t(k)} U_{k i}(\omega) S_{k}\left(R_{(k)}, \omega\right)
$$

where $U_{k i}$ represents the ground motion for a unit constant slip on the subfault $k$ with a given source mechanism, $\omega$ is the angular frequency. Slip $(k), t(k)$ and $S_{k}$ are the slip, the rupture time and the source function of the $k$-th subfault depending on a single variable: the rise time $R(k)$. This simple parameterization limits the number of parameters of the model with respect to the frequency domain technique proposed by Olson and Anderson (1988).

From a practical point of view, each subfault is represented by an array of point sources separated by a distance of less than one sixth of the shortest wavelength. The subfault contributions $U_{k i}$ are obtained by summing the response of these point sources appropriately delayed in time to include the travel-time difference due to the propagation of the rupture front across each subfault. A local rupture velocity is therefore assumed for the integration on a subfault. This local rupture velocity will not be changed in the inversion process. We therefore assumed also that the rupture was unilateral during the earthquake. The point-source Green functions are calculated for the layered velocity model described in table I, using the discrete wave number integration method (Bouchon, 1981) associated with the reflection transmission matrix method (Kennett, 1983). In this study the distance between 2 point sources is $500 \mathrm{~m}$.

Therefore, assuming on each subfault a constant focal mechanism and rupture-velocity, $V_{i}(\omega)$ can be considered a function of $\operatorname{slip}(k)$, $t(k)$ and $R(k)$ if a functional form of the slip function is prescribed (in the following section the influence of this function will be discussed).

\subsection{Inversion procedure}

The parameter vector $p$ and data vector $d$ are related by the function model vector $f$ as $d=f(p)$. In the sections 4.3. and 4.4., the value of the rise time is fixed and the vector $p$ consists of slip $(k)$ and $t(k)$ which appear in eq. (4.1). In section 4.5. the value of the rise time is determined through the inversion procedure and $p$ consists of $R(k)$, slip $(k)$ and $t(k)$. The elements of $d$ consist of complex 3-component displacement spectra from all stations of table II. We used the data from 12 stations: 4 TERRAscope stations (Kanamori et al., 1992), 7 CSMIP accelerometers (CSMIP, 1992) and Lucerne Edison Electric Company accelerometer. The accelerograms are bandpass filtered between $20 \mathrm{~s}$ and $2.0 \mathrm{~s}$ then doubly integrated in the Fourier domain to obtain particle displacements. The synthetics shown later were filtered in the same way. Synthetic and observed wave forms are shown in absolute time. Since there is no absolute time available for Lucerne station, the records are not used in this inversion. Nevertheless, the fit between the synthetics and observed waveshapes at this station is shown.

The $f$ function is a non-linear function of $t(k)$ and $R(k)$. If we assume an initial parameter vector $p_{0}$, we can obtain the iterative solution $p_{k}$ by linearization of $f$ around $p_{0}$ at the first iteration and around $p_{k-1}$ at each subsequent iteration $k$. Using the observed data vector $d_{0}$ and an inversion algorithm based on the 
Table II. Stations.

\begin{tabular}{cccccc}
\hline \hline Station name & Network & Abreviation & Latitude & Longitude & $\begin{array}{c}\text { CSMIP station } \\
\text { number }\end{array}$ \\
\hline Goldstone & TERRAscope & GSC & 35.30 & -116.804 & \\
Pasadena & TERRAscope & PAS & 34.148 & -118.172 & \\
Seven Oak Dam & TERRAscope & SVD & 34.104 & -117.10 & \\
Pinyon Flat Obs. & TERRAscope & PFO & 36.169 & -121.378 & \\
Amboy & CSMIP & AMB & 34.560 & -115.74 & 21081 \\
Barstow & CSMIP & BAR & 34.887 & -117.047 & 23559 \\
Baker & CSMIP & BAK & 35.272 & -116.07 & 32075 \\
Desert Hot Spring & CSMIP & HOT & 33.962 & -116.509 & 12149 \\
Fort Irwing & CSMIP & FOR & 35.268 & -116.68 & 24577 \\
Joshua Tree & CSMIP & JOS & 34.131 & -116.314 & 22170 \\
Lucerne & Edison & LUC & 34.558 & 116.612 & \\
\hline
\end{tabular}

work by Tarantola and Valette (1982), $p_{k+1}$ is given by:

$$
\begin{gathered}
p_{k+1}= \\
=p_{k}+b\left(A_{k}^{t} C_{d}^{-1} A_{k}+C_{p}^{-1}\right)^{-1}\left(A_{k}^{t} C_{d}^{-1}\left(d_{0}-f\left(p_{k}\right)\right)+C_{p}^{-1}\left(p_{0}-p_{k}\right)\right)
\end{gathered}
$$

Here $A_{k}$ is the Jacobian matrix of $f\left(p_{k}\right)$ (the $i j$ th element of $A_{k}$ is

$$
\frac{\partial f_{i}\left(p_{k}\right)}{\partial\left(p_{k}\right)_{j}},
$$

$b$ is a damping constant between 0 and 1 used to prevent divergence, and $C_{p}$ and $C_{d}$ are the covariance matrices for $p$ and $d$. Because a functional form of the slip is assumed, all derivatives are evaluated analytically. Since this problem is intrinsically non-linear the final results depend on the starting model chosen a priori. In the following, 60 frequencies are used. The inversion converges in about 100 iterations (with a damping factor $b$ equal to 0.1 ). The process is stopped when the decrease of the misfit function is less than $0.2 \%$ from one iteration to the next. We assume that off-diagonal element of $C_{d}$ and $C_{p}$ are equal to 0 . The diagonal elements of $C_{d}$ and $C_{p}$ are given by the data and parameter variances. As men- tioned by Hartzell (1989) the estimation of a priori variances in strong-motion inversion is not easy. In the inversion described in sections 4.4 and 4.5 we give a greater weight to the TERRAscope stations which have acquisition systems of higher dynamics by giving smaller variances $\left(C_{d}=0.25\right)$ to those stations compared to the others $\left(C_{d}=1.0\right)$. The final results are comparable to those presented in this paper if the same value of $C_{d}$ is assumed for all the stations. According to Spudich and Frazer (1984) the slip distribution is strongly dependent on the rupture-front velocity. This effect is clearly shown by Cohee and Beroza (1994) in their inversion of Landers strong motions: the slip distributions found with different rupture front velocities between 2.2 and $3.2 \mathrm{~km} / \mathrm{s}$ are very different. Since the most important parameter to reproduce is the time at which each point ruptures, we chose to give the rupture time a greater weight in the inversion than either the slip or the rise time of each subfault. We then assume values of smaller a priori variances for the rise time and the slip $\left(C_{p}=81.0\right)$ than for the time of rupture of each subfault $\left(C_{p}=169.0\right)$. Like Fukuyama and Irikura (1986), Fukuyama and Mikumo (1993) these diagonal values of $C_{p}$ and $C_{d}$ were found after several inversion tests to find the best convergence. 
The observed and synthetic amplitude spectra at each station are equally normalized by the maximum observed amplitude spectra of the three components. This means that, for example, the weight given to each station in our inversion is independent of the distance of the station. Indeed, the directivity effect and decay with distance remain present in our proposed physical model.

\subsection{Quality of the solution: analysis of error and resolution}

The fit to the data at each iteration $k$ is evaluated using the misfit function $S$ (Tarantola and Valette, 1982):

$$
\begin{gathered}
S\left(p_{k}\right)= \\
=\frac{1}{2}\left[\left(f\left(p_{k}\right)-d_{0}\right)^{t} C_{d}^{-1}\left(f\left(p_{k}\right)-d_{0}\right)+\left(p_{k}-p_{0}\right)^{t} C_{p}^{-1}\left(p_{k}-p_{0}\right)\right]
\end{gathered}
$$

Following Cohee and Beroza (1994), we also evaluate the variance reduction between theoretical and observed seismograms defined as

$\Delta \sigma^{2}=1-\frac{\left(d_{0}-f\left(p_{\infty}\right)\right)^{t} C_{d}^{-1}\left(d_{0}-f\left(p_{\infty}\right)\right)}{d_{0}^{t} C_{d}^{-1} d_{0}}$

The resolution matrix Res illustrates how well the inverse problem can be solved with our data.

$\operatorname{Res}=\left(A_{\infty}^{t} C_{d}^{-1} A_{\infty}+C_{p}^{-1}\right)^{-1} A_{\infty}^{t} C_{d}^{-1} A_{\infty}$

The farther the resolution operator is from identity, the worse the resolution is. If the diagonal element of the resolution matrix corresponding to a parameter is equal to 1 , the parameter is perfectly resolved by the data set. The trace (sum of the diagonal elements) of Res indicates the number of parameters effectively resolved by the data. The values of the resolution are dependent on the a priori choice of $C_{p}$ and $C_{d}$. For this reason, the resolution matrix in this study is used in a relative way to compare the relative resolution of different parts of the fault or to compare results obtained with different starting models but the same a priori variances. One can note the absence of positivity constraint in our inversion. This absence of positivity constraints allows a resolution analysis to be performed which is important in strong motion inversions.

\subsection{Importance of the a priori slip function}

All considerations about the value of the rise time must take into account the specific function used to describe the slip. To test the importance of this factor, we considered three different functions acceptable to represent the slip history. As a first stage, we tried to invert the slip distribution and the rupture time of each subfault using the TERRAscope records only and a simple model of the fault. We assumed a given value of the rise time on each subfault and we inverted for slip and rupture time of 16 subfaults $5 \mathrm{~km}$ long and extending in depth from $1 \mathrm{~km}$ to $16 \mathrm{~km}$. In the following inversions, the misfit in the frequency domain is reduced by a factor of 3 with respect to the simple model proposed by Campillo and Archuleta (1993).

We present these three functions in fig. 7a,b together with the Fourier spectra of their derivatives in the frequency band selected for filtering our displacement data. Although the function used in those inversions are roughly similar, their spectra show significant differences in the frequency range relevant to the ground displacement modeling. As a test, we performed the inversion of the slip and rupture time distributions assuming a rise time of $3 \mathrm{~s}$ with the three different slip functions. The results are shown in fig. 8. The different slip functions lead to different absolute values of the slip while the relative distributions are quite similar. A simple explanation of this dependence is the fact that the far-field seismic radiation is proportional to the derivative of the slip function. In spite of the complex configuration of this problem (the vicinity of an extended source), the dependence of the displacement on the slip velocity remains visible. To 

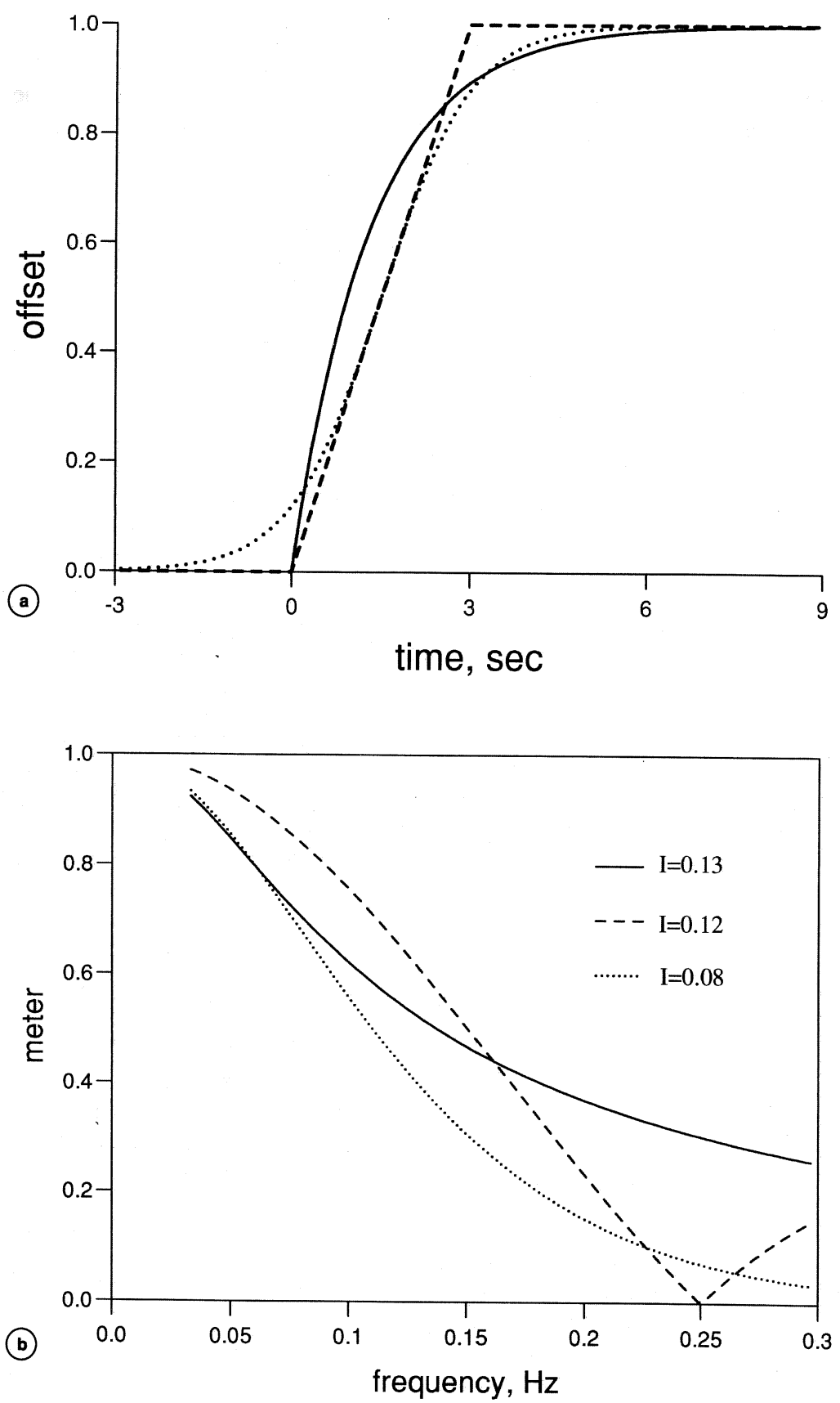

Fig. 7a,b. a) Slip functions used in this study with a rise time equal to $3 \mathrm{~s}$. For a given rise time $R$ the analytical forms of those functions represented with a solid, dotted and dashed line are respectively $S(t)=1 / 2[1+\tanh (t+R / 2.0) * R / 2.0)] ; S(t)=H(t)\left(1-\exp ^{(-2 * t) / R}\right)$ (where $H(t)$ is the Heaviside step function) and a ramp function. b) Spectra of the derivatives of the 3 slip functions depicted in (a). 


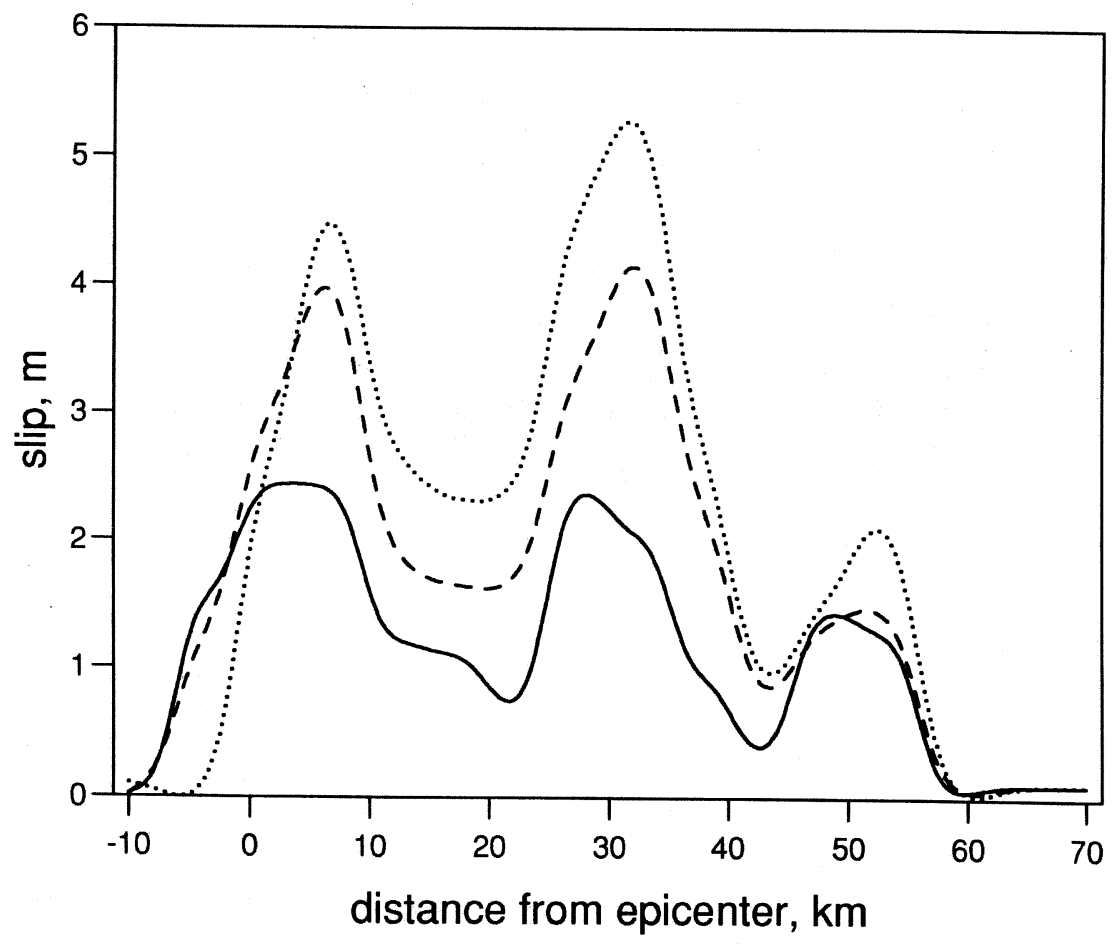

Fig. 8. This figure shows the slip distribution obtained by inversion of the TERRAscope data with the a priori slip functions shown in fig. 7a,b. In this inversion procedure, the fault has been divided into 16 subfaults. Each subfault is $5 \mathrm{~km}$ long and $15 \mathrm{~km}$ large. The curves we show are given by the interpolations of the 16 values obtained through the inversion.

give a simple quantitative consideration, we computed the integral of the slip velocity function spectra in the frequency range relevant to our inversion. The values for the three functions considered are indicated in fig. 7b. The largest slip distribution is obtained when using the slip function associated with the smallest velocity spectrum integral. In the following paragraph, we chose to use the function corresponding to the smooth ramp (denoted by a dotted line on the figures). This function leads to inversion results that are closer to the field observations than the other two tested functions.

\subsection{Test on the rise time}

In order to specify the possible values of the rise time, we performed a series of inversions of the slip and rupture time with different rise times between 1 and $5 \mathrm{~s}$. In those inversions the rise time is constant during the inversion procedure. We inverted for a more complex model with 48 subfaults as described in fig. 9 . The location of the stations used in this study is shown in fig. 10. A rise time of $3.0 \mathrm{~s}$ leads to the smallest misfit (fig. 11). Values of 3.5 or $4.0 \mathrm{~s}$ give similar misfit. On the opposite values of $1.0,2.0$ or $5.0 \mathrm{~s}$ give significantly greater misfit. Since different a priori values of the rise time give different slip distribution, it is important to check the value of the corresponding seismic moment. The seismic moment is known from other studies (fig. 11) to be between $0.8 * 10^{20} \mathrm{~N}-\mathrm{m}$ and $1.1 * 10^{20} \mathrm{~N}-\mathrm{m}$ (Kanamori et al., 1992; Sieh et al., 1993; Murray et al., 1993; Freymueller et al., 1994). Figure 11 also shows the moment obtained from 
Johnson Valley Fault (strike N 354)

[.] Homestead Valley Fault (strike N 331)

$\triangle \nabla$ Emerson and Camp Rock Fault (strike N 322)

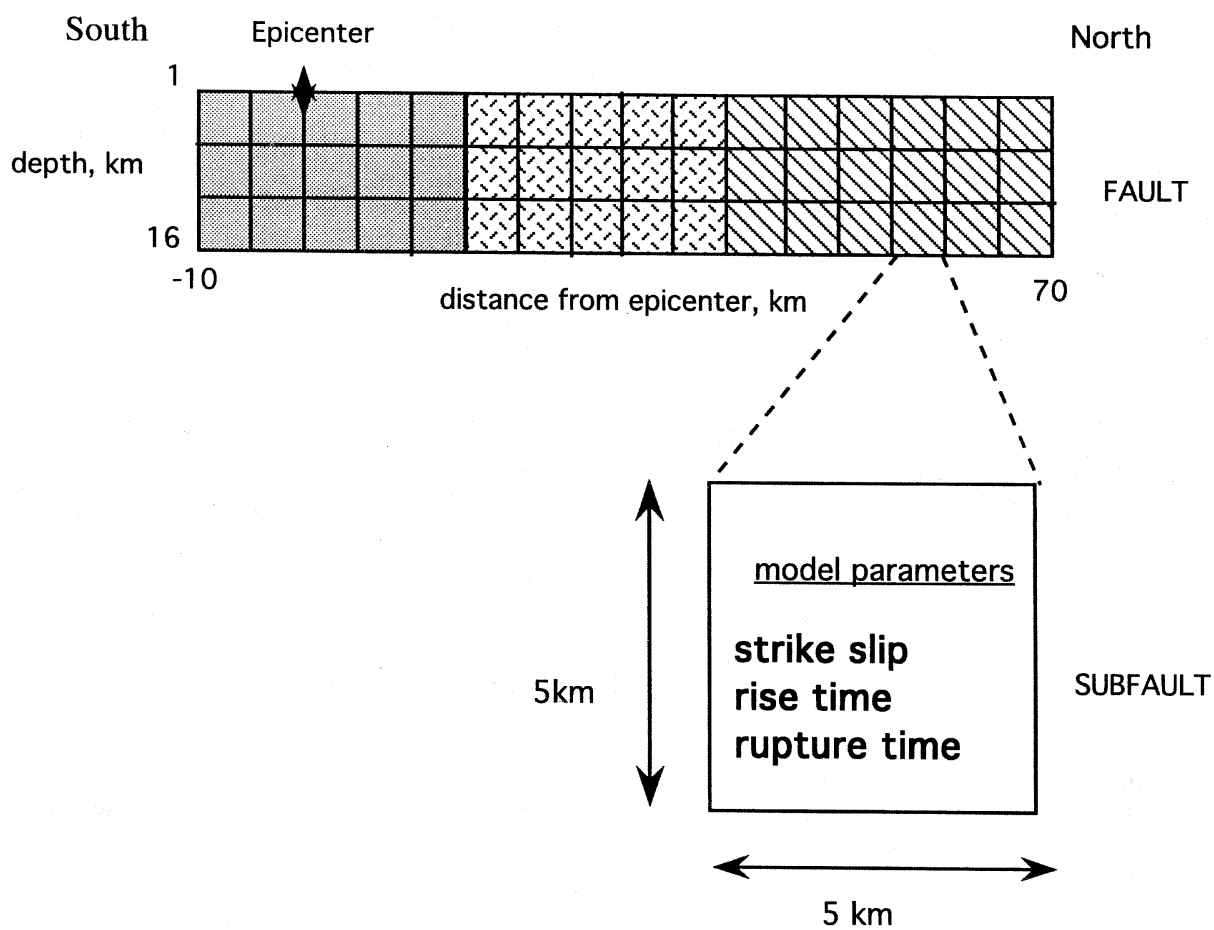

Fig. 9. Fault parameterization used in the inversion of strong motion records. The fault is divided into 48 subfaults for which the model parameters (strike-slip, rupture time and rise time) are inverted. The epicenter defines the coordinate origin and is marked by a star.

our inversion with different rise times. The moment corresponding to the smallest misfit is smaller than the values deduced from long period studies. To make a better agreement between the two evaluations of the moment, we ought to use an even larger rise time in this model. On the contrary, a small rise time value would lead to a larger gap between the two evaluations of the moment. It is important to notice that the choice of one of the two other slip functions described in fig. 8 (dashed line and solid line) would have required an even larger rise time to agree with the known seismic moment.

\subsection{Simultaneous inversion of the rise time}

We introduce now the local rise time as a parameter to be evaluated directly through the inversion of the records. The value of the rise time chosen in our starting model is $4 \mathrm{~s}$. The influence of this a priori value on the final result of our inversion will be discussed in the following.

Figure 12a gives the maps of rupture time, slip and rise time obtained by interpolation of the results of the inversion. Since our inversion is performed in the frequency domain, the modulus of the synthetic and data spectra of all 
the stations are shown in fig. $12 \mathrm{~b}$. To present a usual view of the actual fit, the corresponding observed and synthetic time-histories are shown in fig. 12c. The data are the solid lines and the synthetics are plotted as dashed lines at the same scale. For both models, the horizontal components of the TERRAscope stations (PFO, PAS, SVD and GSC) are very well matched both in amplitude and shape. The other horizontal components and even the Lucerne station which is not considered in our inversion, fit pretty well. Each component is weighted proportionally to the maximum of the spectra of the three components, so the small amplitude vertical components show the smallest variance reduction.

As mentioned above, a strong trade-off is expected between the rupture front velocity and the slip distribution and our model was allowed to have strong variations of rupture front velocities. The most striking feature is that rupture velocity varies strongly with position on the fault. We showed in Cotton and Campillo (1995) that where the slip is large (over the first $10 \mathrm{~km}$ from the epicenter of the Johnson Valley fault at depth, over the Homestead Valley fault between 25 and $40 \mathrm{~km}$ and over the top of the Camp Rock fault between 45 and 50 $\mathrm{km}$ near the surface) the rupture front velocity is well constrained and near $3.0 \mathrm{~km} / \mathrm{s}$.

The total moment of our model is $0.9 * 10^{20}$ $\mathrm{N}-\mathrm{m}$ which is in good agreement with other estimates. Significant slip occurred on all three segments. The Johnson Valley fault has about $20 \%$ of the total moment, the Homestead Valley fault $50 \%$ and the Emerson-Camp Rock fault $30 \%$. Near the hypocenter, in the first part of the Johnson Valley fault, the slip occurred at depth. Most of the energy radiated by the earthquake comes from the Homestead Valley

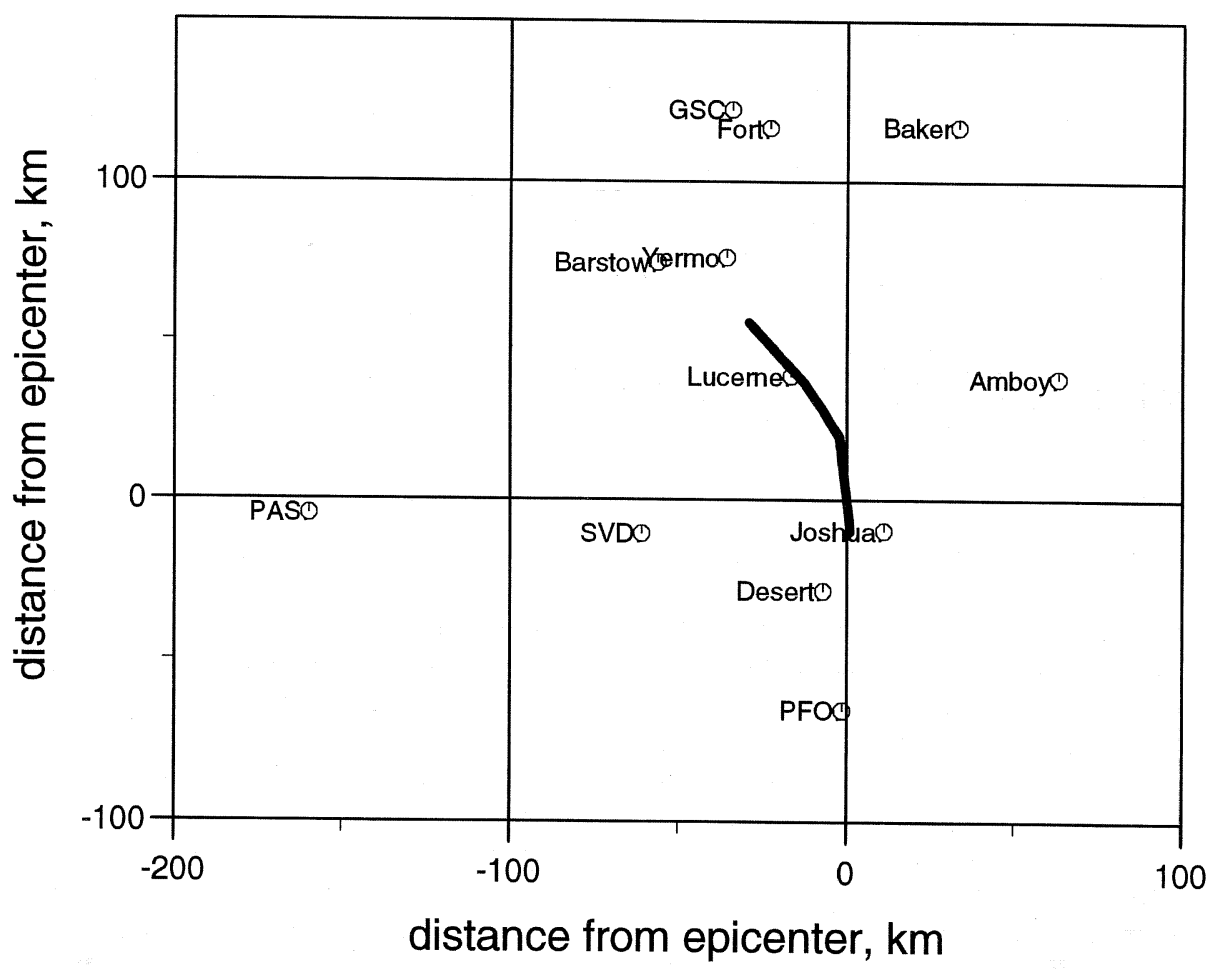

Fig. 10. Locations of the seismic stations used in this study. The stations are listed in table II. The solid line represents the surface projection of the fault model. 

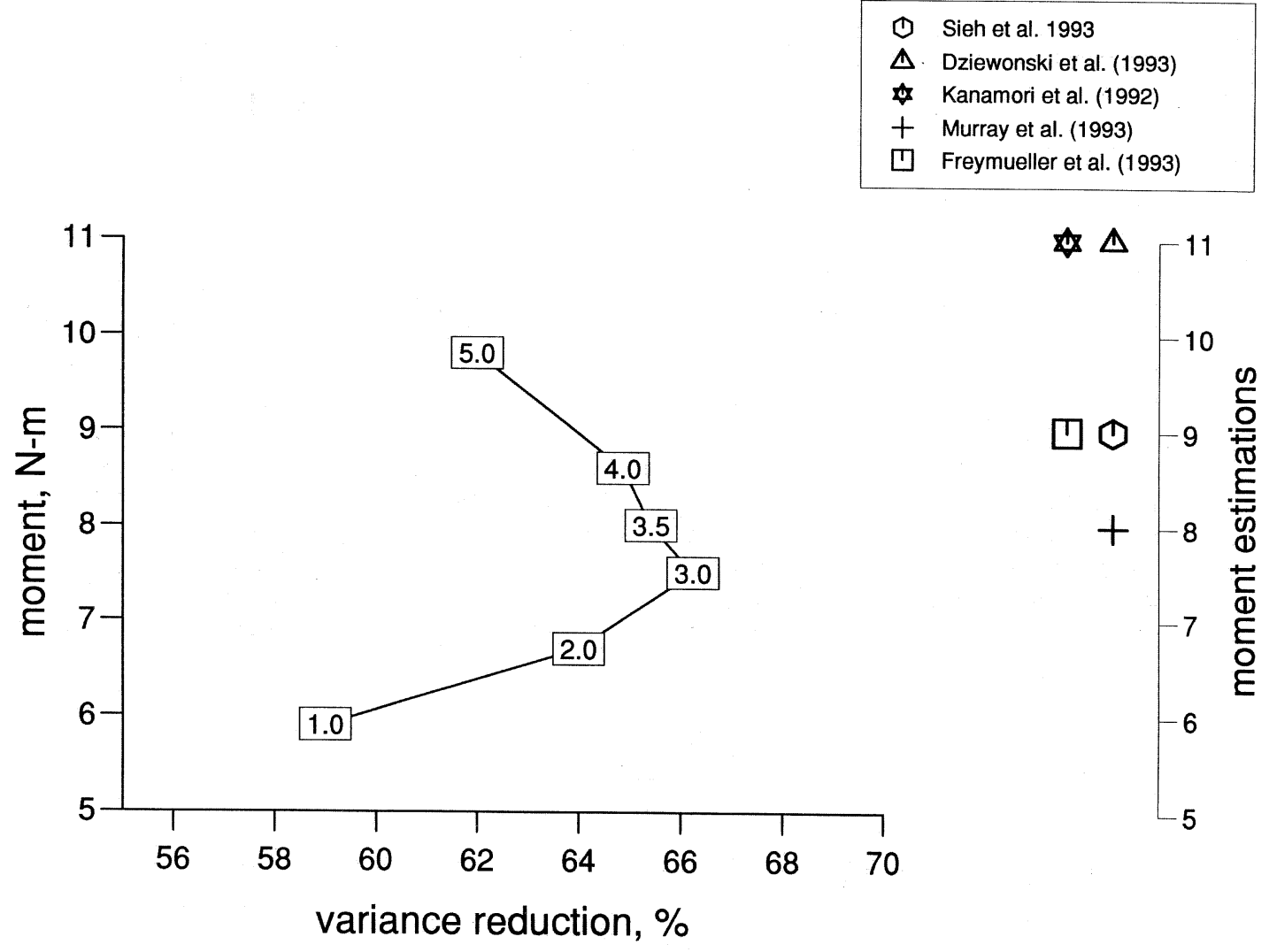

Fig. 11. Misfit and moment deduced from the rupture models computed with different rise times (in boxes) between $2 \mathrm{~s}$ and $6 \mathrm{~s}$ (left). Moment estimations (right) given by geological studies (Sieh et al., 1993), geodesical studies (Freymueller et al., 1994; Murray et al., 1993) and long period wave studies (Kanamori, 1992; Dziewonski, 1993).

fault which is situated between 20 and $40 \mathrm{~km}$ from the epicenter. The Homestead Valley fault is the only part of the fault where the slip occurred on the entire width of the fault. Slip is important on the Camp Rock fault, but in this part of the fault, the rupture is shallower.

An important feature of our inversion method is that the rise time on each subfault is directly inverted. The rise time distribution is heterogeneous. The rise time is larger (more than $4 \mathrm{~s}$ ) near the hypocenter and along the Johnson Valley fault than on the Homestead
Valley fault and Camp Rock fault. In these regions of high moment release, most of the values of the rise time are between 3.0 and $4.0 \mathrm{~s}$.

Since our inversion is non linear, we have to test the influence of the choice of the rise time in the starting model on our final results. We already noticed that values of rise time of about 3-4 s lead to realistic values of the seismic moment. Nevertheless, it is important to check if the inversion of our data alone gives a strong constraint on the value of the rise time. 
We performed a series of inversions with initial values of the rise time between $1 \mathrm{~s}$ and $5 \mathrm{~s}$. The results obtained are summarized in table III where the final mean value of the rise time on the zones of high moment release are given. When considering a priori low values as 1 s or $2 \mathrm{~s}$, the inversion converges to larger final values close to $3 \mathrm{~s}$. On the contrary, when considering a priori values of $4 \mathrm{~s}$ or $5 \mathrm{~s}$, the inversion tends to decrease the rise time. Indeed, the a priori value of the rise time gives the final value in the regions of low slip where the resolution is weak. This test shows that the value of the rise time is clearly constrained in a region of high slip by the data used in this study.

The distance over which rupture is occurring simultaneously is given by the product of rupture velocity by rise time. According to our results, this distance is at least 9 kilometers (if
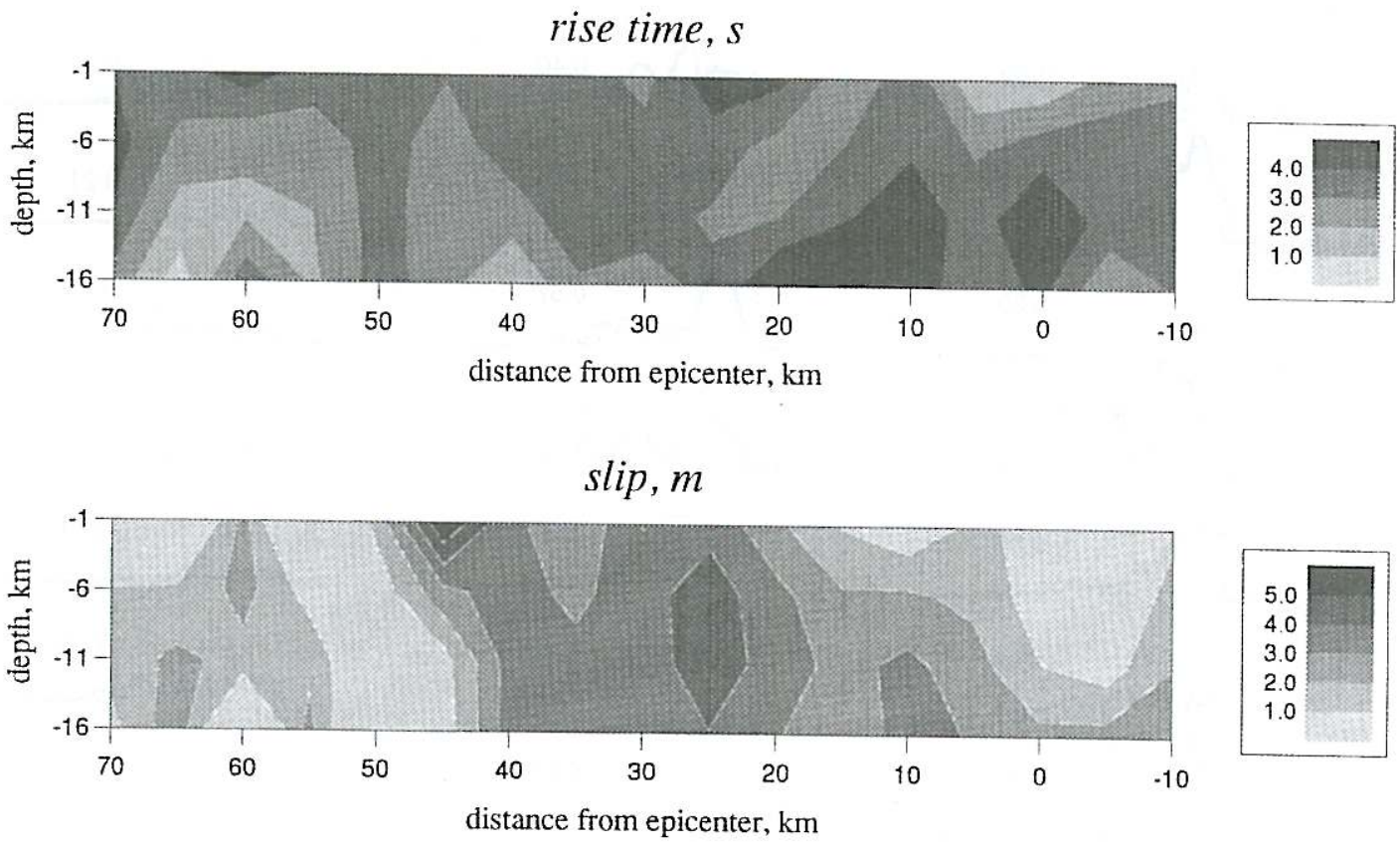

distance from epicenter, $\mathrm{km}$

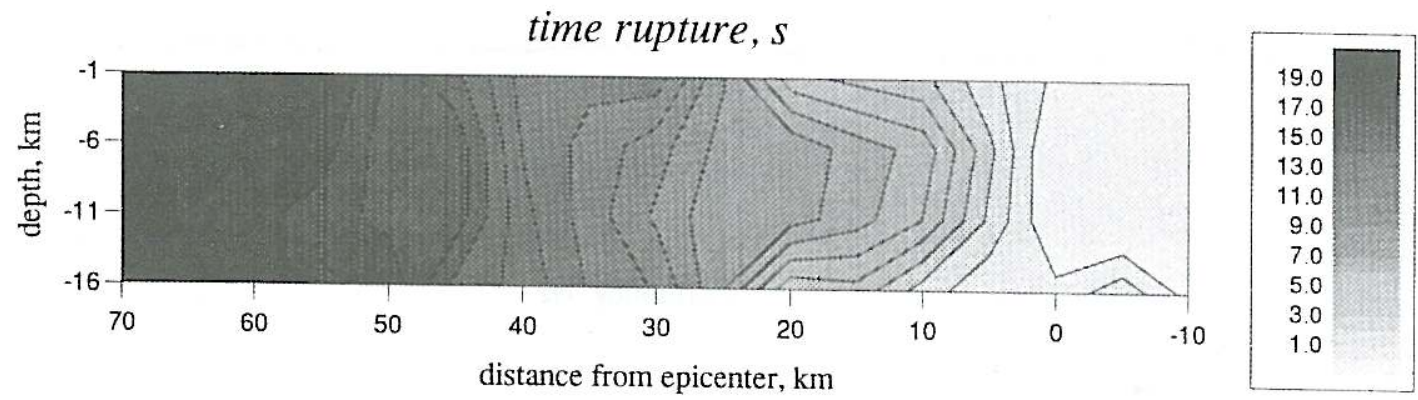

Fig. 12a. Maps of rupture time, slip and rise time obtained by interpolation of the inversion results. The $2 \mathrm{~s}$ contours are plotted on the map of rupture time to show the evolution of the rupture front. 
$N-S$

$E-W$

$U-D$

Lucerne
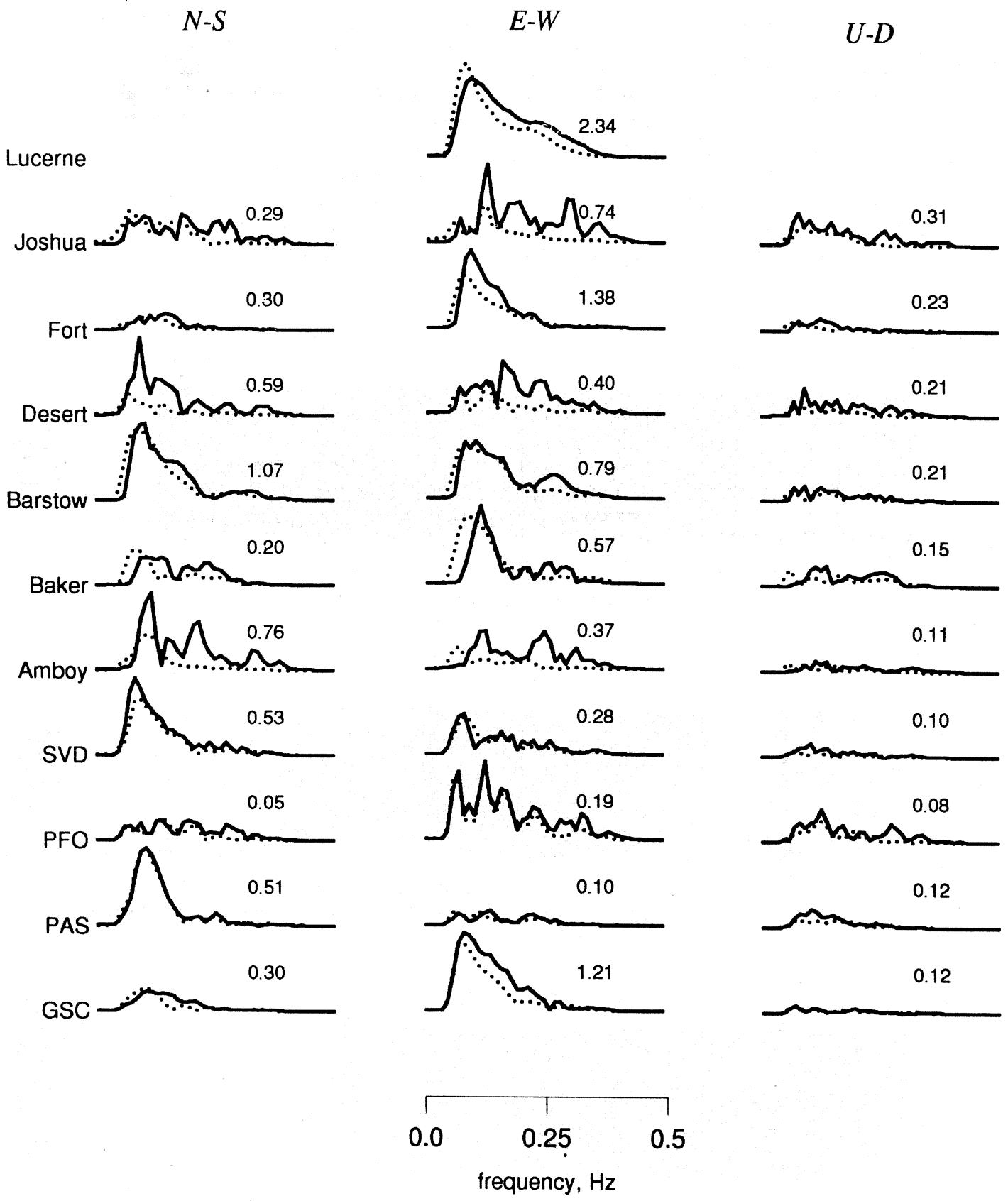

Fig. 12b. Modulus of the observed spectra (solid line) and synthetic spectra (dashed). The maximum in ms of each data amplitude spectrum is shown to the right of each pair. In each case synthetics and observations are plotted at the same scale. 

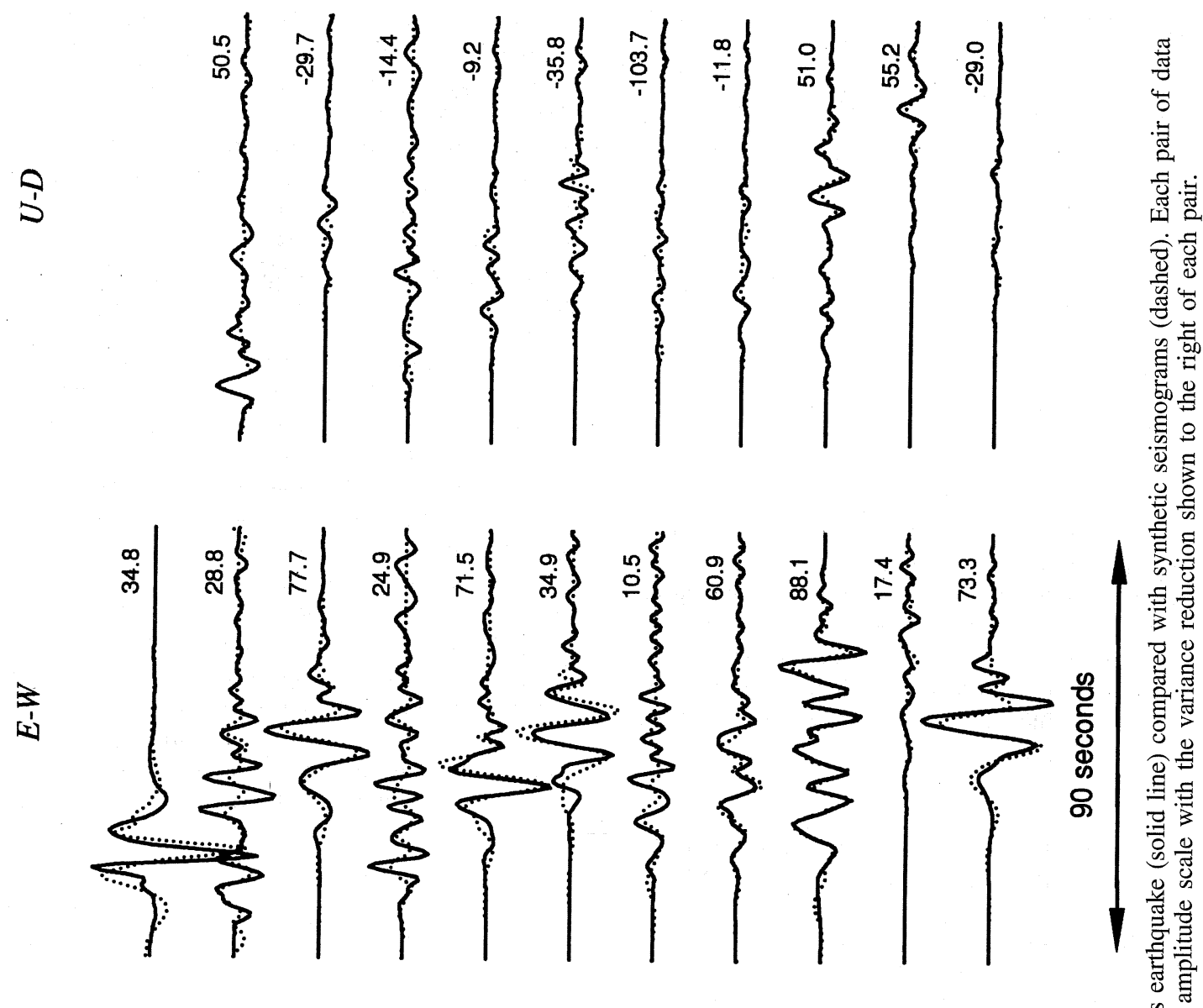

\begin{tabular}{l} 
옹 \\
80 \\
8 \\
8 \\
8 \\
\hline 8
\end{tabular}

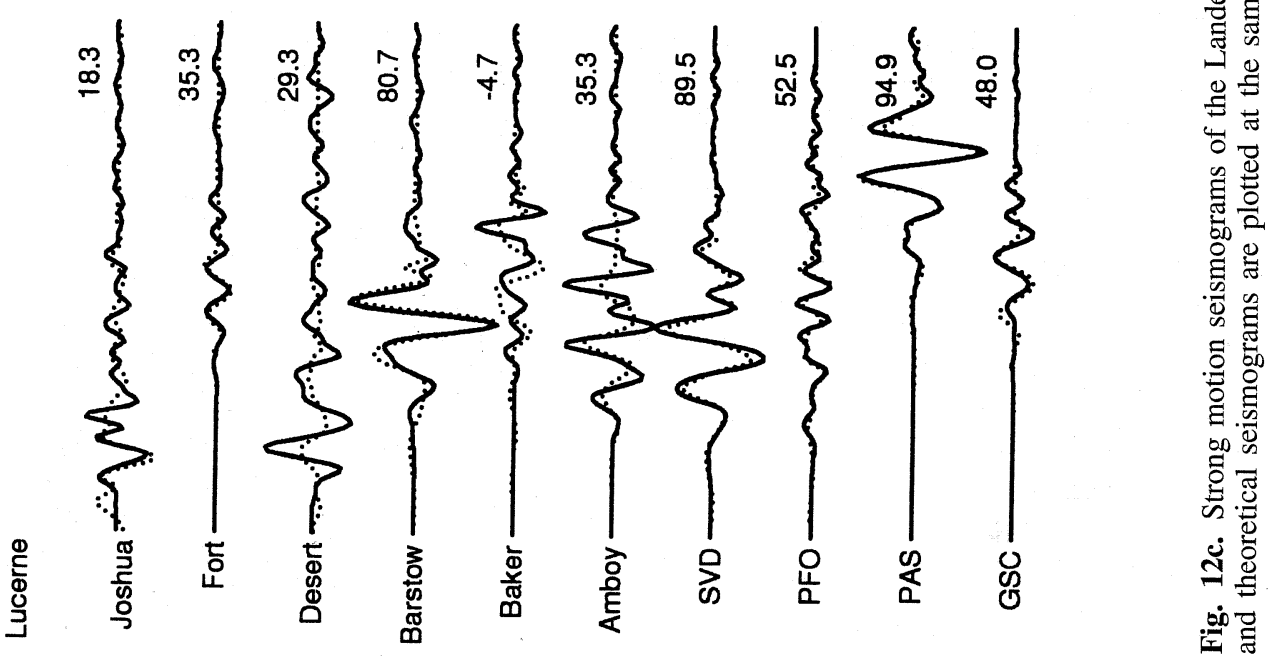


Table III. Final mean values of the rise time obtained with different a priori values.

\begin{tabular}{cc}
\hline $\begin{array}{c}\text { Initial rise time on } \\
\text { each subfault }(\mathrm{s})\end{array}$ & $\begin{array}{c}\text { Mean rise-time at the } \\
\text { end of the inversion } \\
\text { (subfaults with } \\
\text { slip > 3.0 m) }\end{array}$ \\
\hline 1.0 & 2.74 \\
2.0 & 2.62 \\
3.0 & 2.83 \\
4.0 & 3.37 \\
5.0 & 4.01 \\
\hline
\end{tabular}

we consider a mean velocity of $3.0 \mathrm{~km} / \mathrm{s}$ on the region of high slip release as seen above). The regions of high slip (sub-events) have characteristic dimensions between 10 and 20 kilometers which is $50 \%$ to $100 \%$ of the typical distance on which the rupture is developing. One can note that the rise time is larger in the hypocentral area.

\subsection{Control of our results: resolution analysis and comparison with other observations}

Resolution of the inversion is shown in fig. 13. This resolution map gives us an idea of the regions of the fault where our inversion is well constrained by the data. The rise time resolution is poor on the Johnson Valley fault. On the other hand, the resolution is good in the region of high slip. In these regions of high moment release the mean value of the rise time ranges between 3.0 and $4.0 \mathrm{~s}$. The same feature was found by Wald and Heaton (1994) who mention a duration in the order of $4 \mathrm{~s}$ in the regions of high slip (near 30-35 km at mid-depth and for the shallow slip peak at about 40-50 $\mathrm{km}$ along the strike). Nevertheless they found a smaller value of the rise time $(2 s)$ in other parts of the fault where our inversion shows a poor resolution.

Our source model shows a good agreement with those resulting from other studies. We present in fig. 14 the distribution of slip at the surface measured directly by the geologists in the field (Sieh et al., 1993) and the surface slip inferred from our inversion. The agreement is surprisingly good owing to the fact that our values are integrated over $5 \mathrm{~km}$. Geodetic analysis indicates that in the northern end of the fault, the slip occurred essentially near the surface (Bock et al., 1992; Blewitt et al., 1992). A similar pattern can be seen in our results. We found that the fault extends in depth south of the epicenter. The study of guided waves trapped in the fault zone of Li et al. (1994) leads to a similar conclusion. Inversions of local, teleseismic data or even geodetic data have been performed by Cohee and Beroza (1994) or Wald and Heaton (1994). Most of the differences between all the proposed models occur on the Johnson Valley fault and the adjacent section of the Homestead Valley fault. On the other hand, a common characteristic of all the models is a high moment release on the Homestead Valley fault and a shallow rupture on the Camp Rock fault. A possible explanation for those discrepancies is the spatial variation of the resolution of those three different inversions. For example, our inversion shows a low resolution at depth for the Johnson Valley fault.

\subsection{Comparison with other inversions of the rise time}

Dislocation rise time is one of the most difficult parameters to extract from the data. As demonstrated above, the consideration of this parameter has to take into account the fit to the data but also the respect for the total moment. This point was already noted by Hartzell and Mendoza in their study of the 1978 Tabas, Iran, earthquake (1991). He compared a short (0.7 s) simple triangular source-time function with a modified Kostrov function with a duration of $2.9 \mathrm{~s}$. Although the wave forms used in this inversion cannot resolve between these two time functions, the function with longer rise time gives a moment estimate and maximum fault displacement more consistent with long period surface waves and field observations (table IV). Another important point is the spatial variation of the rise time. Hartzell and Heaton 


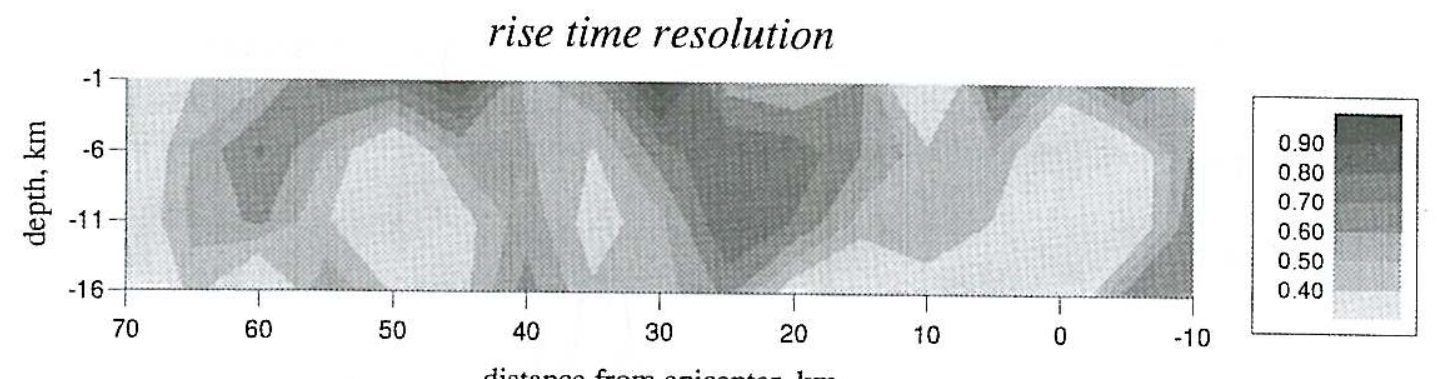

distance from epicenter, $\mathrm{km}$

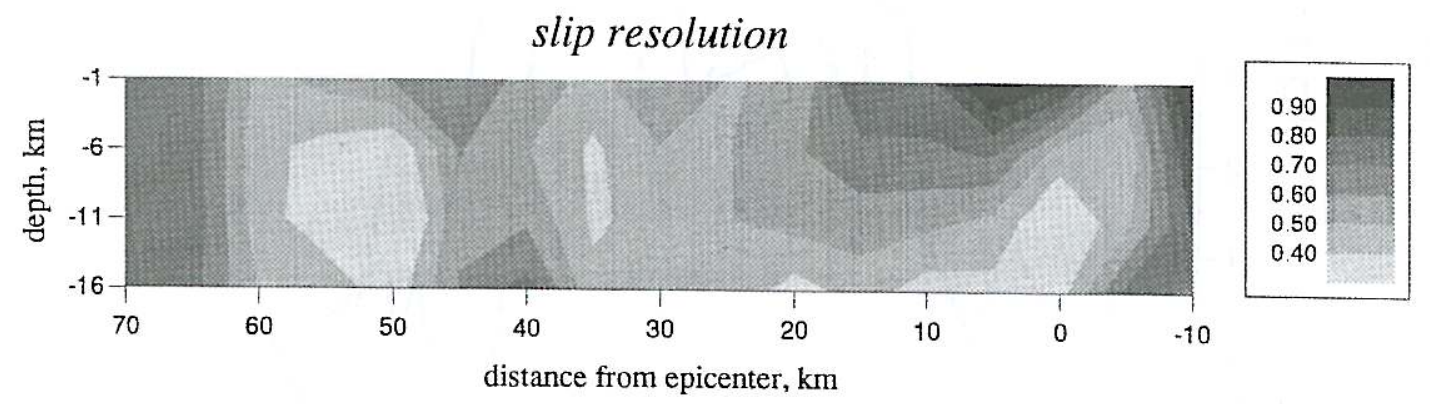

rupture time resolution

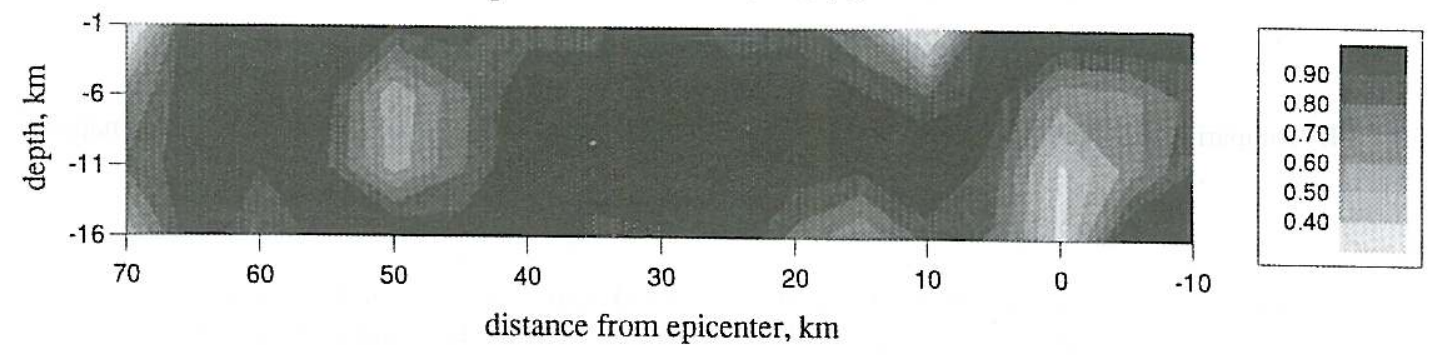

Fig. 13. Maps of rise time, slip and rupture time resolution. These maps are obtained by interpolation of the resolution matrix diagonal value calculated for each inverted parameter. Since those values depend on the choice of the a priori variance of each parameter, these maps are used for relative comparisons of the resolution in different parts of the fault.

(1983) showed that inversions that assume constant rupture velocity and rise time can lead to false results with slip patterns around the hypocenter and low total moment. In recent years, several studies have tried to specify the values of this parameter through inversion procedures which allow significant spatial varia- tions of the source time function along the fault plane. Different procedures have been used to include the rise time as a free parameter in the inversion:

- The first approach is a discretization of the total rupture duration of each subfault 


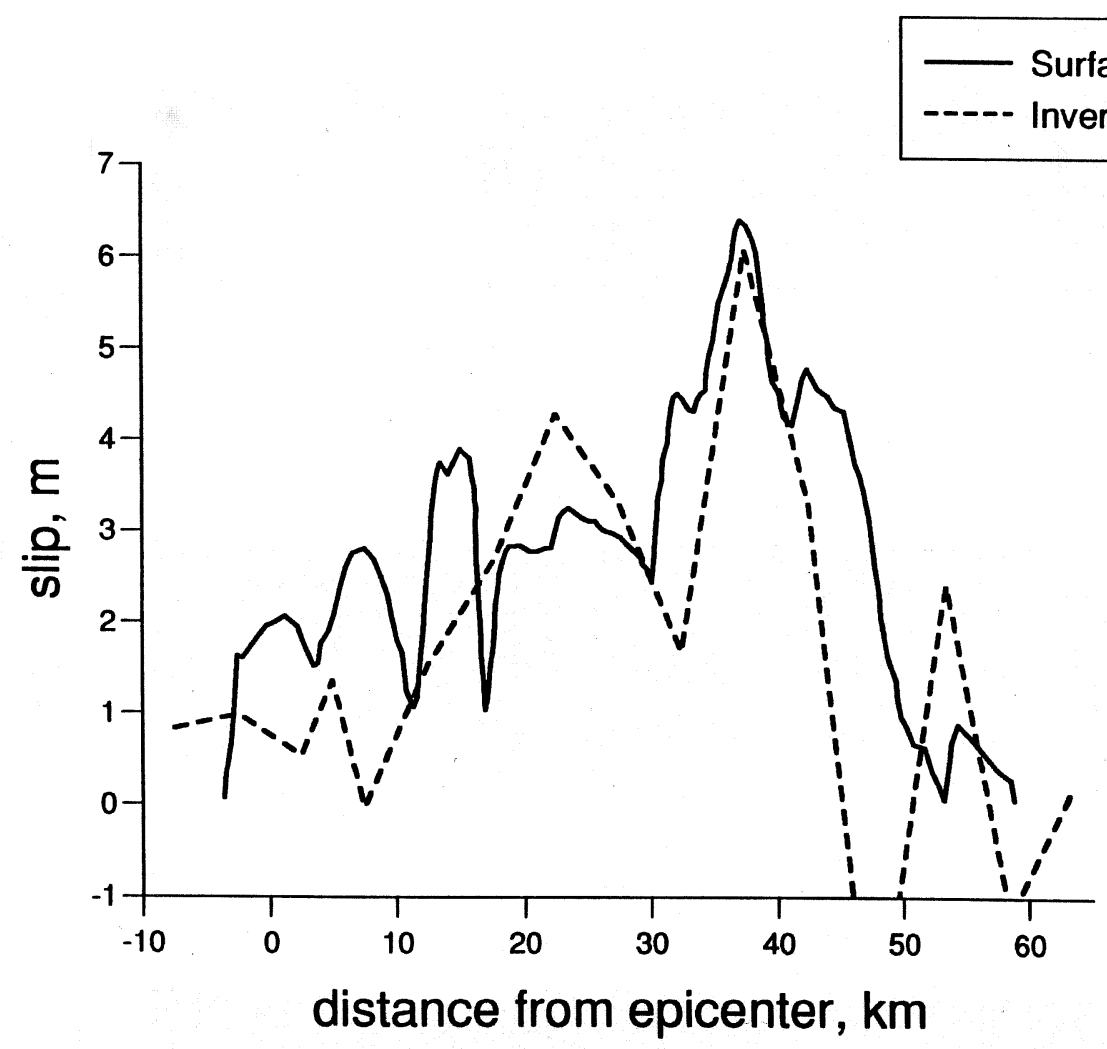

Fig. 14. Comparison of fault slip solutions for the subfaults situated at the top of the fault and the mapped surface slip.

(Hartzell and Heaton, 1983, 1986; Wald et al., 1990, 1991; Hartzell and Mendoza, 1991; Hartzell and Langer, 1993; Mendoza et al., 1994; Wald and Heaton, 1994). An elementary source-time function is used for each discrete rupture interval of each subfault. Each subfault is allowed to slip several times, allowing the possibility of a longer slip duration. In this way, general rise time functions can be constructed that vary as a function of the position on the fault. In this procedure, a maximum rupture velocity needs to be chosen that gives the earliest possible time at which any point on the fault may fail, the subfault is required to fail within the allowed time window (which also gives the maximum rise time) and the number of unknowns increases with each addi- tional time interval added to the discretized rise time. In earlier studies using this time window parameterization (Hartzell and Heaton, 1983, 1986; Wald et al., 1990, 1991) three time windows were employed. With the improvement of computational capabilities the number of time windows has increased (14 in Mendoza et al., 1994) and more freedom has been given to the rise time and the rupture velocity.

- The frequency domain inversion method of Olson and Anderson (1988) and Mendez et al. (1990) was used to study the Michoacan earthquake (Mendez and Anderson, 1991). This approach places no a priori restrictions on the source rise time or rupture velocity. However, good data coverage is required to obtain a stable solution (Olson and Anderson, 1988). 
Table IV. Rupture parameters.

\begin{tabular}{|c|c|c|c|c|c|c|c|c|c|c|}
\hline Earthquake & $\begin{array}{c}\text { Moment } \\
\left(10^{25}\right. \\
\text { dyne-cm) } \\
\mathbf{L P}^{\mathrm{a}} \\
I N V^{\mathrm{b}}\end{array}$ & $\begin{array}{c}l \\
\mathrm{~km}\end{array}$ & $\begin{array}{c}w \\
\mathrm{~km}\end{array}$ & $\begin{array}{c}l_{a} \\
\mathrm{~km}\end{array}$ & $\begin{array}{c}V_{r} \\
\mathrm{~km} / \mathrm{s}\end{array}$ & $\frac{2 l_{a}}{3 V_{r}}$ & $\begin{array}{c}\text { Type of } \\
\text { the data } \\
\text { used }\end{array}$ & $\begin{array}{l}\text { Rise time } \\
\text { found by... }\end{array}$ & $\begin{array}{l}\text { Rise } \\
\text { time (s) } \\
\text { mean } \\
\text { high } \\
\text { slip } \\
\text { region }\end{array}$ & Reference \\
\hline $\begin{array}{c}3 / 3 / 85 \\
\left(M_{w}=8.0\right) \\
\text { Central Chile }\end{array}$ & $\begin{array}{l}1200 \\
1500\end{array}$ & 220 & 90 & 50 & 3.0 & 11.1 & $\begin{array}{l}\mathrm{NF}^{\mathrm{c}} \\
\mathrm{TEL}^{\mathrm{d}}\end{array}$ & $\begin{array}{c}\text { multiple } \\
\text { windowing }\end{array}$ & 14 & $\begin{array}{l}\text { Mendoza et al. } \\
\text { (1994) }\end{array}$ \\
\hline $\begin{array}{c}15 / 9 / 78 \\
\left(M_{s}=7.4\right) \\
\text { Tabas, Iran }\end{array}$ & $\begin{array}{c}\mathbf{1 5 0} \\
52\end{array}$ & 90 & 40 & 12 & 2.5 & 3.2 & $\begin{array}{l}\text { NF } \\
\text { TEL }\end{array}$ & $\begin{array}{l}\text { trial error (no } \\
\text { spatial variation } \\
\text { allowed) }\end{array}$ & 0.7 & $\begin{array}{c}\text { Hartzell and } \\
\text { Mendoza (1991) }\end{array}$ \\
\hline $\begin{array}{c}15 / 9 / 78 \\
\left(M_{s}=7.4\right) \\
\text { Tabas, Iran }\end{array}$ & $\begin{array}{l}\mathbf{1 5 0} \\
130\end{array}$ & 90 & 24 & 12 & 2.5 & 3.2 & $\begin{array}{l}\text { NF } \\
\text { TEL }\end{array}$ & $\begin{array}{l}\text { trial error (no } \\
\text { spatial variation } \\
\text { allowed) }\end{array}$ & 2.9 & $\begin{array}{l}\text { Hartzell and } \\
\text { Mendoza (1991) }\end{array}$ \\
\hline $\begin{array}{c}3 / 10 / 74 \\
\left(M_{w}=8.0\right) \\
\text { Peru }\end{array}$ & $\begin{array}{l}\mathbf{1 5 0 0} \\
1500\end{array}$ & 250 & 100 & 50 & 3.0 & 11.1 & TEL & $\begin{array}{c}\text { multiple } \\
\text { windowing }\end{array}$ & 18.0 & $\begin{array}{l}\text { Hartzell and } \\
\text { Langer (1993) }\end{array}$ \\
\hline $\begin{array}{c}9 / 11 / 74 \\
\left(M_{s}=7.1\right) \\
\text { Peru }\end{array}$ & 63 & 40 & 20 & 10 & 3.0 & 2.22 & TEL & $\begin{array}{c}\text { multiple } \\
\text { windowing }\end{array}$ & 2.0 & $\begin{array}{l}\text { Hartzell and } \\
\text { Langer (1993) }\end{array}$ \\
\hline $\begin{array}{c}24 / 11 / 87 \\
\left(M_{s}=6.6\right) \\
\text { Superstition } \\
\text { Hill }\end{array}$ & $\begin{array}{l}7.2 \\
4.8\end{array}$ & 20 & 5 & 7 & 2.4 & 1.9 & $\mathrm{NF}$ & $\begin{array}{c}\text { multiple } \\
\text { windowing }\end{array}$ & 1.0 & $\begin{array}{l}\text { Wald et al. } \\
\text { (1990) }\end{array}$ \\
\hline $\begin{array}{c}19 / 9 / 85 \\
\left(M_{w}=8.0\right) \\
\text { Michoacan }\end{array}$ & $\begin{array}{l}1100 \\
1100\end{array}$ & 170 & 80 & 50 & 2.8 & 11.9 & $\mathrm{NF}$ & $\begin{array}{l}\text { frequency domain } \\
\text { inversion (Mendez } \\
\text { et al., 1990) }\end{array}$ & 8.0 & $\begin{array}{c}\text { Mendez and } \\
\text { Anderson (1991) }\end{array}$ \\
\hline $\begin{array}{c}18 / 10 / 89 \\
\left(M_{s}=7.1\right) \\
\text { Loma Prieta }\end{array}$ & $\begin{array}{c}\mathbf{2 0 - 3 4 ^ { e }} \\
35\end{array}$ & 47 & 18 & 10 & 3.0 & 2.22 & $\mathrm{NF}$ & $\begin{array}{c}\text { trial-error } \\
\text { (no spatial } \\
\text { variation allowed) }\end{array}$ & 1.0 & $\begin{array}{l}\text { Steidl et al. } \\
\quad \text { (1991) }\end{array}$ \\
\hline $\begin{array}{c}18 / 10 / 89 \\
\left(M_{s}=7.1\right) \\
\text { Loma Prieta }\end{array}$ & $\begin{array}{c}\mathbf{2 0 - 3 4 ^ { e }} \\
30\end{array}$ & 40 & 20 & 10 & 2.7 & 2.46 & $\begin{array}{l}\text { NF } \\
\text { TEL }\end{array}$ & $\begin{array}{c}\text { multiple } \\
\text { windowing }\end{array}$ & $1.0<$ & $\begin{array}{l}\text { Wald et al. } \\
\text { (1991) }\end{array}$ \\
\hline $\begin{array}{c}\text { 20/02/90 } \\
\text { (Mjma = 6.5) } \\
\text { Izu-Oshima, } \\
\text { Japan }\end{array}$ & 4.0 & 19 & 14 & 7 & $2.5 ?$ & 1.86 & NF & $\begin{array}{l}\text { calculated from the } \\
\text { slip functions } \\
\text { found by the } \\
\text { dynamic inversion }\end{array}$ & 7.0 & $\begin{array}{l}\text { Fukuyama and } \\
\text { Mikumo } \\
(1993)\end{array}$ \\
\hline $\begin{array}{c}28 / 06 / 92 \\
\left(M_{s}=7.3\right) \\
\text { Landers }\end{array}$ & $\begin{array}{c}110 \\
70\end{array}$ & 70 & 15 & 15 & 2.7 & 3.7 & $\begin{array}{l}\text { NF } \\
\text { TEL }\end{array}$ & $\begin{array}{c}\text { multiple } \\
\text { windowing }\end{array}$ & $\begin{array}{l}2.0 \\
4.0\end{array}$ & $\begin{array}{c}\text { Wald and } \\
\text { Heaton (1994) }\end{array}$ \\
\hline $\begin{array}{c}28 / 06 / 92 \\
\left(M_{s}=7.3\right) \\
\text { Landers }\end{array}$ & $\begin{array}{c}110 \\
90\end{array}$ & 70 & 15 & 15 & 3.0 & 3.33 & NF & $\begin{array}{l}\text { directly found } \\
\text { through the } \\
\text { inversion }\end{array}$ & 3.5 & $\begin{array}{l}\text { Cotton and } \\
\text { Campillo } \\
\text { (1994) }\end{array}$ \\
\hline
\end{tabular}

${ }^{\mathrm{a}}$ Moment estimated with long period study; ${ }^{\mathrm{b}}$ moment calculated from the slip distribution deduced from the inversion;

${ }^{c}$ near-field data; ${ }^{\mathrm{d}}$ teleseismic data; ${ }^{\mathrm{e}}$ for a review see Wald et al., 1994. 
- Another approach was proposed by Fukuyama and Mikumo (1993): a waveform inversion has been applied to strong motion data using a dynamic shear crack model. The slip time function at each subfault has been calculated from the final dynamic rupture model. From these slip functions, they calculate the rise times which are defined as the time until the slip reaches $95 \%$ of the final slip.

- In this paper, the value of the rise time is directly evaluated through an inversion procedure performed in the frequency domain. Strong spatial variations are allowed and the number of unknowns is limited by specifying the a priori form of the slip function.

In table IV we present the results of all those inversions. Following Heaton (1990), we give for each inversion a rise time derived from this inversion (mean rise time or rise time in region of high moment release) and rise times that would be expected if the duration of the slip is comparable to the time required to rupture the dominant asperity, in which case we would expect the dislocation rise time to be approximated by (Day, 1982; Heaton, 1990):

$$
T_{S} \approx \frac{2 l_{a}}{3 V_{r}}
$$

$l_{a}$ and $V_{r}$ are the characteristic dimensions of the dominant asperity and the mean rupture velocity. The approximate rupture length $l$ and the approximate rupture width $w$ are also given and for each earthquake we try to give a comparison between the moment calculated from the slip model deduced from the inversion and the moment evaluated with long period studies. We can note the very small duration (less than $1 \mathrm{~s}$ ) of the rise time found for the Loma Prieta earthquake (Steidl et al., 1991; Wald et al., 1991; Beroza, 1991). In this case the rise time is much lower than the time required to break the dominant asperity $(2.5 \mathrm{~s})$. On the contrary, other studies with the same inversion procedure as the studies of the 1985, Central Chili, earthquake (Mendoza et al., 1994) or the 1974, Peru, earthquake (Hartzell and Langer, 1993) show long rise time (respectively $14 \mathrm{~s}$ and $18 \mathrm{~s}$ ) consistent with the time to rupture the lo- cal asperity. Those recent results, together with our study of the Landers earthquake indicate that the rise time could be of the same order as what we expected from the breakage of an asperity.

\section{Conclusions}

The example of the Michoacan earthquake shows that a crack type model is in this case more appropriate than a dislocation model to describe the displacement record just above the fault. We also showed that this point is not in contradiction with the fact that the faulting appears to be a complex process. We attributed this complexity to instabilities in crack growth.

The Landers earthquake was recorded by numerous stations with an acceptable azimuthal coverage. Therefore we used an inversion process to describe the slip history. Our final results are in a good agreement with other reliable observations. According to our resolution analysis the rise time values seem to be constrained only in a region of high moment release. In those regions of high slip the mean value of the rise time is between 3.0 and $4.0 \mathrm{~s}$.

The typical distance on which rupture is developing simultaneously is given by the product of rupture velocity by rise time. According to our results, this distance is around $10.0 \mathrm{~km}$ in the regions of high moment release, that is roughly the dimension of these regions. The large earthquake studied here consists in three subevents. The analysis of the displacements favors the hypothesis that the duration of slip at a point of the fault is of the order of the rupture time of a subevent. This behavior corresponds to a crack type process, as we defined it in the introduction of this paper, for each subevent. However, the slip duration is much smaller that the total duration of the earthquake as previously argued by Heaton (1990).

\section{Acknowledgements}

We thank R. Archuleta, A. Mendez and P. Spudich for their suggestions to improve this work. The reviews by an anonymous reviewer 
and $\mathrm{M}$. Cocco improved the original manuscript. Thanks are given to J. Boatwright, G. Beroza, T. Heaton and R. Madariaga for their comments during the Erice meeting.

\section{REFERENCES}

AкI, K. (1968): Seismic displacement near a fault, J. Geophys. Res., 73, 5358-5376.

AKI, K. and P.G. Richards (1980): Quantitative Seismology (W.H. Freeman, San Francisco).

Anderson, J.G., P. Bodin, J.N. Brune, J. Prince, S.K. Singh, R. QuaAs and M. Onate (1986): Strong ground motion from the Michoacan, Mexico earthquake, Science, 233, 1043-1048.

BerozA, G.C. (1991): Near-source modeling of the Loma Prieta earthquake: evidence for heterogeneous slip and implications for the earthquakes hazards, Bull. Seismol. Soc. Am., 81, 1603-1621.

Blewitt, G., M.B. Heflin, K.J. Hurst, D.C. JefFerson, F.H. Webi and J.F. Zumberge (1992): Absolute far-field displacements from the 28 June 1992 Landers earthquake sequence, Nature, 361, 340-342.

Bock, Y., D.C. Agnew, P. Fang, J.F. Genrich, B.H. Hager, T.A. Harring, K.W. Hudnut, R.W. King, S. Larsen, J.B. Minster, K. Stark, S. Wdowinsky and F.K. WyatT (1992): Detection of crustal deformation from the Landers earthquake sequence using continuous geodetic measurements, Nature, 361, 337-339.

Bouchon, M. (1981): A simple method to calculate Green's function for layered media, Bull. Seismol. Soc. Am., 71, 959-971.

BRUNE, J.N. (1970): Tectonic stress and the spectra of seismic shear waves from earthquakes, J. Geophys. Res., 75, 4997-5009.

Brune, J.N., P.A. Johnson and C. Slater (1990): Nucleation, predictability and rupture mechanism in foam rubber models of earthquake, J. Himalayan Geology, 1, 155-166.

Campillo, M., J.C. Gariel, K. Aki and F.J. Sanchez-Sesma (1989): Destructive strong ground motion in Mexico city: source, path, and site effects during great 1985 Michoacan earthquake, Bull. Seismol. Soc. Am., 79, 1718-1735.

Campillo, M. and R.J. Archuleta (1993): A rupture model for the 28 June 1992 Landers, California Earthquake, Geophys. Res. Lett., 20, 647-650.

Cohee, B.P. and G.C. Beroza (1994): Slip distribution of the 1992 Landers earthquake and its implications for earthquake source mechanism, Bull. Seismol. Soc. Am., 84, 692-712.

Cotton, F. and M. Campillo (1995): Frequency domain inversion of strong motions: application to the 1992 Landers earthquake, J. Geophys. Res. (in press).

CSMIP, 1992: Processed CSMIP strong-motion records from the Landers, California earthquake of June 1992, Calif. Dept. of Conserv. Reports, Sacramento, CA.

DAs, S. and K. AKI (1977): A numerical study of two dimentional spontaneous rupture propagation, Geophys. J.R. Astron. Soc., 62, 591-604.

DAS, S. and B. V. Kostrov (1988): An investigation of the complexity of the earthquake source time function using dynamic faulting models, J. Geophys. Res., 93, 8035-8050.

DAY, S. (1982): Three-dimentional finite difference simulation of faults dynamics: rectangular faults with fixed rupture velocity, Bull. Seismol. Soc. Am., 72, 705727.

Dziewonski, A.M., G. Ekström and M.P. SAlganik (1993): Centroid-moment tensor solutions for April-June 1992, Phys. Earth. Planet. Inter., 77, 151-163.

Freymueller, J., N.E. King and P. Segall (1994): Coseismic slip distribution of the 1992 Landers earthquake, Bull. Seismol. Soc. Am., 84, 646-659.

Fukuyama, E. and K. IrikuRa (1986): Rupture process of the 1983 Japan Sea earthquake using a waveform inversion method., Bull. Seismol. Soc. Am., 76, 16231640.

Funuyama, E. and T. Mikumo (1993): Dynamic rupture analysis: inversion for the source process of the 1990 , Japan, earthquake, J. Geophys. Res., 98, 6529-6542.

Hartzell, S.H. (1989): Comparison of seismic waveform results for the rupture history of a finite fault: application to the 1896 North Palm Springs, California, earthquake, Bull. Seismol. Soc. Am., 94, 7515-7534.

Hartzell, S.H. and T.H. Heaton (1983): Inversion of strong ground motion and teleseismic waveform data for the fault rupture history of the 1979 Imperial Valley, California, earthquake, Bull. Seismol. Soc. Am., 73, 1553-1583.

Hartzell, S.H. and T.H. Heaton (1986): Rupture history of the 1984 Morgan Hill, California earthquake from the inversion of strong motions records, Bull. Seismol. Soc. Am., 76, 649-674.

Hartzell, S. and C. Mendoza (1991): Application of an iterative least-squares waveform inversion of strong-motionand teleseismic records to the 1978 Tabas, Iran, earthquake, Bull. Seismol. Soc. Am., 81, 305-331.

HARTZELL, S. and C. LANGER (1993): Importance of model parameterization in finite fault inversion: application to the $1974 M w 8.0$ Peru earthquake, J. Geophys. Res., 98, 22123-22134.

HeatoN, T.H. (1990): Evidence for and implication of selfhealing pulses of slip in earthquakes rupture, Phys. Earth Planet. Inter., 64, 1-20.

Houston, H. and K. KANAMORI (1986): Source characteristics of the 1985 Michoacan, Mexico, earthquake at period of 1 to 30 seconds, Geophys. Res. Lett., 13, 597600.

Kanamori,.H. and D. Hadley (1975): Crustal structure and temporal velocity change in Southern California., Pure Appl. Geophys., 113, 257-280.

Kanamori, H., H. Thio, D. Dreger, E. Hauksson and T.H. Heaton (1992): Initial investigation of the Landers California earthquake of 28 June 1992 using TERRAscope, Geophys. Res. Lett., 19, 2267-2270.

KennetT, B.L.N. (1983): Seismic wave propagation in stratified media (Cambridge University Press, Cambridge).

Kostrov, B. V. (1964): Unsteady propagation of longitudinal shear cracks, Appl. Math. Mech., 28, 1241-1248.

Li, Y.G., K. Aki, D. Adams, A. Hasemi and W. Lee (1994): Seismic guided waves trapped in the fault zone of the 
Landers, California, earthquake of 1992, J. Geophys. Res., 99, 11705-11722.

MAdARIAGA, R. (1976): Dynamics of an expanding circular fault, Bull. Seismol. Soc. Am., 66, 636-666.

Madariaga, R. and A. Cochard (1992): Heterogeneous faulting and friction, International symposium on earthquake disaster prevention, Mexico.

Mendez, A.J., A.H. Olson and J.G. Anderson (1990): A norm minimization criterion for the inversion of earthquake ground-motion ground-motion records, Geophys. J. Int., 81, 287-298.

Mendez, A.J. and J.G. Anderson (1991): The temporal and spatial evolution of the 19 september 1985 Michoacan earthquake as inferred from near-source ground-motion records, Bull. Seismol. Soc. Am., 81, 844-861.

Mendoza, C., S. Hartzell and T. Monfrey (1994): Wideband analysis of the 3 march 1985 Central Chili earthquake: overall source process and rupture history, Bull. Seismol. Soc. Am., 84, 269-283.

Murray, M.H., J.C. Savage, M. Lisowski and W.K. Gross (1993): Coseismic displacements: 1992 Landers, California, earthquake, Geophys. Res. Lett., 20, 623-626.

Olson, A.H. and J.G. ANDERSON (1988): Implications of frequency-domain inversion of earthquake ground motion for resolving the space-time dependence of slip on an extended fault, Geophys. J., 94, 443-455.

Sanchez-Sesma, F.J., S. Chavez-Perez, M. Suarez, M.A. Bravo and L.E. Perez-Rocha (1988): On the seismic of the valley of Mexico, Earthquake Spectra, 4, 568588.

SIEH, K., L. JONES et al. (1993): Near-field investigation of the Landers earthquake sequence, April to July 1992 , Science, 260, 171-176.

Singh, S.K., A. Mori, E. Mena, F. Krüger and R. Kind (1990): Evidence for anomalous bodywave radiation between 0.3 and $0.7 \mathrm{~Hz}$ from the 1985 September 19 Michoacan, Mexico earthquake, Geophys. J. Int., 101, 37-48.

Spudich, P. and L.N. Frazer (1984): Use of ray theory to calculate high-frequency radiation from earthquake sources having spatially variable rupture velocity and stress drop, Bull. Seismol. Soc. Am., 74, 2061-2082.

Steidl, J.H., R.J. Archuleta and S.H. Hartzell (1991): Rupture history of the 1989 Loma Prieta, California, earthquake, Bull. Seismol. Soc. Am., 81, 1573-1602.

Tarantola, A. and B. Valette (1982): Generalized nonlinear inverse problem solved using the least squares criterion, Rev. Geophys. Space Phys., 20, 219-232.

Wald, D.J., D.J. Helmberger and S.H. Hartzell (1990): Rupture process of the 1987 Superstitions Hills earthquake from the inversion of strong motion data, Bull. Seismol. Soc. Am., 80, 1079-1098.

Wald, D.J. and T.H. Heaton (1991): Rupture model of the 1989 Loma Prieta earthquake from the inversion of strong-motion and broadband teleseismic data, Bull. Seismol. Soc. Am., 81, 1540-1572.

WaLD, D.J. and T.H. Heaton (1994): Spatial and temporal distribution of slip for the 1992 Landers, California, earthquake, Bull.. Seismol. Soc. Am., 3, 668-691.

YomogIDA, K. (1988): Crack-like rupture processes observed in near-fault strong motion data, Geophys. Res. Lett., 15, 1223-1226. 